\title{
Dynamic Analysis of Monopile Supported Offshore Wind Turbines
}

\author{
K A Abhinav \\ Research Scholar, \\ Department of Ocean Engineering, Indian Institute of Technology, Madras \\ Chennai 600036 \\ Nilanjan Saha* \\ Associate Professor, \\ Department of Ocean Engineering, Indian Institute of Technology, Madras \\ Chennai 600036 \\ * Corresponding Author: nilanjan@iitm.ac.in, Ph: +91-44-2257-4827, FAX: +91-044-2257-4802
}

\section{Abstract}

This paper describes the stochastic dynamic response of NREL 5MW offshore fixedbased wind turbines (OWT) under various soil conditions - medium dense sand, stiff clay and layered profiles in $20 \mathrm{~m}$ water depth. The aerodynamic and hydrodynamic OWT loads are derived using the force-controlled approach. Usually the OWT generates power in an operational regime and survives at extreme wind speeds. Therefore, two met-ocean conditions adhering to irregular JONSWAP spectrum are considered-one in an operational regime (average wind speed $V_{w}=12 \mathrm{~m} / \mathrm{s}$, significant wave height $H_{s}=4 \mathrm{~m}$, and peak spectral period $\left.T_{p}=10 \mathrm{~s}\right)$ and another near cut-out regime $\left(V_{w}=22 \mathrm{~m} / \mathrm{s}, H_{s}=10 \mathrm{~m}, T_{p}=14 \mathrm{~s}\right)$. The soil is modelled via a non-linear ground to spring model. For each sea-state, time domain stochastic responses are calculated and the ensemble average response is calculated from 50 Monte-Carlo simulations. The change in ensemble average response is described due to changes in pile penetration depth and diameter of the piles for the three soil configurations.

Results indicate that the dynamic response mainly depends on the stiffness of the soil and reiterate the need for detailed site-specific geotechnical investigations before designing OWT foundations. 
33 Abbreviations

34 AF Apparent fixity

35 API American Petroleum Institute

36 DNV Det Norske Veritas

37 FATBM Fore-aft tower bending moment

38 FE $\quad$ Finite element

$39 H_{S} \quad$ Significant wave height

40 IEA International Energy Agency

41 IEC International Electrotechnical Commission

42 JONSWAP Joint North Sea Wave Project

43 MW Mega Watt

44 MSL Mean sea level

45 NREL National Renewable Energy Laboratory

46 OWT Offshore wind turbine

47 RNA Rotor-nacelle-assembly

48 SSI Soil structure interaction

49 TWh Terawatt-hours

$50 \quad T_{P} \quad$ Peak spectral period

$51 V_{W} \quad 10$-min average wind speed at hub-height

$521 \mathrm{P} \quad$ rotor frequency

53 3P blade-pass frequency for 3 bladed OWT

54

Introduction

Offshore wind is considered as a dependable and reliable source of renewable energy.

57 By the end of 2018, offshore wind is expected to supply 76 TWh of electricity around the world (IEA, 2013). Offshore winds are stronger, stable and less turbulent when compared to those blowing over land (Bilgili et al., 2011). These result in higher productivity, as power generated is directly proportional to the cube of wind speed. OWTs are free from the issues

61 of land acquisition, visual and noise impact. However, the additional consideration of lateral

62 loading from waves and currents results in expensive foundations; accounting for up to 50\%

63 of the total cost of an offshore wind farm (Gavin et al., 2011). 
OWTs in shallow waters (depth less than $30 \mathrm{~m}$ ) are supported on steel monopiles,

which are tubular steel sections, driven into the seabed, till a suitable penetration depth is attained (typically between $10-40 \mathrm{~m}$ ). The base of the tower supporting the OWT is connected to the monopile by means of a transition piece. Intermediate to deep waters call for other sub-structural concepts such as tripods and jackets while ultra-deep waters require floating platforms (Abhinav and Saha, 2017). The load transfer mechanism to the soil is different for structures installed in shallow waters with respect to deep waters. While the monopile transmits the lateral loads to the soil by virtue of the bending action, the tripods and jackets transfer global moments as axial forces into the soil (Schaumann and Boker, 2005). For instance, a monopile diameter may vary from $4-6 \mathrm{~m}$ and their penetration depths can be up to $35 \mathrm{~m}$ below the mudline.

OWT problems had been investigated by ignoring the contribution of soil structure interaction (Gao et al., 2010 and Guanche et al., 2013), by assuming the substructures are rigidly clamped to the sea bed i.e., ignoring the effects of the soil in calculating the global response. While this would be a reasonable assumption in a rigid soil, the introduction of the pile-soil regime could significantly alter the natural frequency and the response of the OWT system in softer soils. Under such conditions, the inclusion of SSI in the study becomes critical (Bazeos et al., 2002, Bhattacharya et al., 2013). Damgaard et al., (2014) investigated the dynamic response of OWTs on monopiles, wherein SSI was modelled using a lumpedparameter approach in the aerodynamic code HAWC2 (Larsen, 2009). The inclusion of SSI influenced the fatigue characteristics of the OWT and densification effects in soil(Guo et al., 2015, Nikitas et al., 2017).

Pile foundations supporting OWT structures are subjected to heavy lateral dynamic loading, from winds and waves. This is a marked departure from other offshore structures, for instance, oil platforms, where the vertical loading dominates. The method involving $p-y$ 
89

90

91

(soil resistance-deflection) curves recommended by the standards (API-RP-2A-WSD, 2014, API-RP2GEO, 2011) is widely used for the design of laterally loaded offshore piles. However, the applicability of the $p-y$ method, towards the design of large diameter offshore monopiles has been widely questioned in literature. $p-y$ curves were developed for small diameter flexible piles without taking into consideration scale effects for larger diameters (Lesny and Wiemann, 2005). However, OWT monopiles are large in diameter, show rigid behaviour and merely rotates under lateral loading, leading to the 'toe-kick' phenomenon (Augustensen et al., 2009). Even though OWT monopiles may be subjected to over $10^{9}$ load cycles during their design life, $p-y$ curves have been calibrated for less than 200 cycles (Achmus and Abdel-Rahman, 2012). Latest OWT standards (DNV OSJ101, 2014) have suggested that for large diameter monopiles, $p-y$ curves should be used with caution after validation with numerical methods. However in the paper, soil stiffness curves have been generated using finite element based Winkler-Springs formulations.

Aeroelastic simulation codes like FAST (Jonkman and Buhl, 2005), HAWC2 and BLADED (Bossanyi, 2000) do not have the capability for detailed modelling of non-linear SSI. OWTs being an interdisciplinary area calls for the coupling of these specialized computer programs in each area (aeroelastic, hydrodynamic and geotechnical) into a generalpurpose FE software, for detailed modelling of the structure and foundation under dynamic loading. Several approaches have been followed in literature for integrating aerodynamic loads with hydrodynamic loads for OWTs. Gao et al., (2010), conducted a decoupled analysis by importing nacelle forces for a jacket supported OWT from the aerodynamic code HAWC2. In ABS (2011), it was suggested that one needs to perform multiple realizations of FAST runs to identify the resultant maxima of shear forces and overturning moments at the tower base and mudline and, to define load cases for structural analysis, considering various support structure configurations. Bisoi and Haldar (2014) conducted a parametric study on a 
monopile supporting an OWT in clayey soil where the aerodynamic load was modelled as a sinusoidal force at the nacelle.

In the present work, FAST (Jonkman and Buhl, 2005) is used for deriving the aerodynamic loads on a monopile supported OWT in shallow waters. Stochastic analyses are performed by importing the time varying loads on the OWT-monopile model into USFOS (SINTEF Group, 2001), wherein ensemble averaged responses (displacements at seabed and tower top) are investigated for different soil properties. USFOS is a nonlinear Lagrangian based finite element code with hydrodynamic and geotechnical capabilities. Aerodynamic loads acting at the tower top are calculated by means of the 'force-controlled' method mentioned in Passon and Branner (2013). This paper compares the variation in the nonlinear stochastic dynamic response of an OWT with a monopile substructure under different turbulent wind speeds and irregular sea-states, with respect to soil conditions. The effects of changes in pile penetration depth and pile diameter on the dynamic response have also been detailed. Finally, sensitivity analyses have been performed to quantify the influence of soil property variation within a particular soil type on the lateral response of the OWT structure.

In this paper, a methodology is proposed to obtain the response of fixed OWT under combined wind and wave loads. Soil (sand and clay) properties are studied by varying their parameters (cohesion, friction angle, etc.) in a deterministic way. To start with, since the applied loads (wind and wave) on the OWT are random, Monte Carlo simulations are necessary. Without having knowledge of the number of samples (random seeds) necessary for convergence, one cannot be sure of the response as each response is just a realization of the random quantity. The realization refers to the time domain response (displacement, shear force, bending moment, etc.) obtained after applying a combination of turbulent wind $\left(V_{W}\right)$ and irregular wave $\left(H_{S}, T_{P}\right)$ loads using a seed for each of these random variables. After seed convergence, the natural frequencies for OWT are obtained after considering soil 
parameters and the collapse analysis for OWT is performed for obtaining ultimate loads.

140 Then the pile penetration depth, pile diameter and sea states are varied deterministically,

141 which gives an idea of how the response (e.g., lateral displacement) changes. This response is

142 obtained by taking the average of all the maxima of the time domain realizations. So any

143 point in the figure in this study is an average of 50 time domain simulations. The statistical

144 parameters of shear force and bending moment are also shown. Usually, the designers are interested in mean and standard deviation; however, the extremes are likely to vary considerably. This is left to the judgement of the designers depending on the cost feasibility.

A 3D FE model of a monopile supported OWT in $20 \mathrm{~m}$ water depth is developed in USFOS. The NREL 5-MW baseline OWT (Jonkman et al., 2009) is considered in the study. The properties of the NREL 5-MW OWT are detailed in Table 1. The OWT is supported by a cylindrical tower, which is connected to the monopile by means of a transition piece. The rotor-nacelle-assembly (RNA) is represented as a point mass on top of the tower. The tower base is located $10 \mathrm{~m}$ above the mean sea level (MSL) and it extends to $87.6 \mathrm{~m}$ above MSL. The diameter and thickness of the tower base are $6 \mathrm{~m}$ and $27 \mathrm{~mm}$ respectively. At the tower top, the corresponding values are $3.87 \mathrm{~m}$ and $19 \mathrm{~mm}$ respectively. The structural details of the tower are derived from Jonkman et al. (2009). The transition piece between the offshore wind turbine tower and the monopile has a diameter of $6.275 \mathrm{~m}$ and is $65 \mathrm{~mm}$ thick. The transition piece is $15 \mathrm{~m}$ long. The supporting (mono) pile is of $6 \mathrm{~m}$ diameter and $65 \mathrm{~mm}$ thickness. A standard embedment depth of 6 times the pile diameter $(36 \mathrm{~m})$ in the soil (Barltrop and Adams, 1991, Aranya et al. 2017) is considered. Steel of density $8500 \mathrm{~kg} / \mathrm{m}^{3}$ is used as a material. The higher value of steel density takes into consideration bolts, welds and flanges that are ignored while obtaining the tower thickness values (Jonkman et al., 2009). The OWT 

6 87

model is developed using a series of step tapered beams in USFOS. Conceptual and FE models of the OWT structure are shown in Figure 1.

Three different soil profiles are considered. The first one is a layered soil profile, which is representative of geotechnical conditions existing off the west coast of India. It consists of interspersing layers of clay and sand of varying strength (personal communication from a leading oil company based in India). The second profile is of medium dense sand (API-RP-2A-WSD, 2014) and the third soil profile is of uniform stiff clay. The properties of the three soil profiles are shown in Table 2. Here, $\gamma^{\prime}$ refers to the effective unit weight of soil, $\Phi$ stands for the angle of internal friction, $\mathrm{S}_{\mathrm{u}}$ is the undrained shear strength, $\varepsilon_{50}$ stands for the strain at half the failure stress and $K$ refers to the initial modulus of subgrade reaction. For clay, the values of $\varepsilon_{50}$ have been selected from Reese and van Impe (2011). Also, the empirical constant ' $J$ required for developing $p-y$ curves in clay is taken as 0.5 (Reese and van Impe, 2011, API-RP-2A-WSD, 2014, API-RP-2GEO, 2011).

\section{Met-ocean Conditions}

Two met-ocean states are considered - an 'operational' condition with significant wave height $H_{S}=4 m$ and spectral peak period $T_{P}=10 \mathrm{~s}$ (Sivakholundu et al., 2014) and another 'near cut-out regime' defined by of $H_{S}=10 \mathrm{~m}$ and $T_{P}=14$ s (Li et al., 2011). 10-min mean wind speeds $V_{W}=12 \mathrm{~m} / \mathrm{s}$ and $V_{W}=22 \mathrm{~m} / \mathrm{s}$ are respectively used in conjunction with the above met-ocean conditions. These wind speeds are applied at hub-height of a wind turbine. In this paper, the term met-ocean condition refers to the combination of wind $\left(V_{W}\right)$ and sea state parameters $\left(H_{S}, T_{P}\right)$. 


\section{Finite Element Model of OWT}

The OWT structure is modelled in the FE code USFOS, which is an acronym for Ultimate Strength of Framed Offshore Structures, is widely used in the offshore industry. USFOS is capable of performing progressive collapse analysis of offshore structures and is based on an updated Lagrangian formulation valid for large displacements and small strains. Here, the load is applied in increments and the system stiffness equations are solved at each step thereby constituting a complete nonlinear analysis on the basis of updated information derived from the previous steps. Two-noded beam-column elements with three each of translational and rotational degrees of freedom at each end are used for modelling the OWT structure.

USFOS allows for pile-soil interaction by inserting nonlinear soil spring-to-ground elements along the length of the pile. The model is 3-dimensional, as both lateral and axial springs are applied to each node. The properties of the spring-to-ground elements are defined through soil curves. The stiffness curves for axial load transfer, end-bearing and lateral resistance are derived from a Winkler spring based formulation in a finite element framework. The stiffness parameter matched well with the values obtained using mobilized strength design method (Bouzid et al. 2013). The soil stiffness for stiff clay are developed using the procedure outlined in Reese et al. (1975) which were also checked using Bouzid et al. (2013). For layered soil, a method involving the computation of equivalent depths of soil layers (Reese and van Impe, 2011) is used. The thickness of the soil layer, in effect, defines the FE mesh density of the piles, as each layer is represented using a unique $p-y$ curve or lateral stiffness property. Finer mesh densities may be obtained by subdividing a thicker soil layer into smaller ones (SINTEF Group, 2001). 
This section deals with the selection of the time-step and soil-spring density for the dynamic analysis. Also, the capability of USFOS to accurately model geotechnical contexts is validated with existing literature.

\section{Time-step convergence}

Choosing an optimal time-step size $(d t)$ is important for any dynamic analysis.

Accuracy increases with decrease in time-step size, however, at the expense of computational costs. A typical time-step convergence study (Figure 2a) was reported for the operational met-ocean sea-state, for the pile head displacement of an OWT supported in stiff clay. On the basis of this study a value of $d t=0.01 \mathrm{~s}$ was chosen for the remaining part of the work. All the soil types for both operational as well as near cut-out met-ocean conditions show convergence at $d t=0.01 \mathrm{~s}$.

\section{Soil-spring density}

The other convergence study that is necessary is the number of springs for each layer of soil. The geotechnical analysis is carried out such that one node is placed at the centre of each soil layer. The piles are modelled as non-linear beam elements joining these nodes. Nonlinear lateral and axial soil-springs are introduced at each node with the properties of the corresponding soil layer. In the code USFOS, mesh density for the soil domain refers to the thickness of the layer. A convergence study for soil-spring density was performed on the monopile foundation and an optimal spacing of $4 \mathrm{~m}$ was obtained, as shown in Figure $2 \mathrm{~b}$. Both stiff clay and medium dense soil profiles were considered and mudline loads representative of a realistic $2 \mathrm{MW}$ OWT, horizontal load $\mathrm{H}=4.6 \mathrm{MN}$ and bending moment $\mathrm{M}$ 
= $95 \mathrm{MNm}$ from Augustensen et al. (2009) were used. The pile diameter and penetration depth were $6 \mathrm{~m}$ and $36 \mathrm{~m}$ respectively. For the layered soil, a varied spacing scheme is required for spring elements. For layers with a thickness less than $4 \mathrm{~m}$, one spring was inserted into the centre of the layer. For thicker layers, a centre-to-centre spacing of $4 \mathrm{~m}$ was used.

\section{Validation}

The modelling and suitability of USFOS for analyzing geotechnical cases have been ascertained by comparison with a previous study by Passon (2006), using the finite-difference based lateral pile analysis code LPILE as shown in Figure 2c. A layered sandy soil of increasing stiffness reproduced in Table 3 from Passon (2006) was used only for the validation exercise.

The time domain analysis in USFOS has been validated, by comparison with a commercial program SESAM Wind (DNV GL, 2016) for fixed OWT structures. Table 4 shows the ensemble averaged results for tower top displacement for a monopile fixed at the bottom (i.e., without soil effects), under a range of varying wind speeds. The analyses are of $660 \mathrm{~s}$ in duration. It is observed that the results predicted by USFOS closely match the output from SESAM Wind.

\section{Loads on the OWT}

The OWT is subjected to lateral dynamic loads from wind, wave, and currents. The bending action of the monopile accounts for the safe transfer of the loads into the soil. The effect of drag action of the wind on the supporting tower is ignored in this study. Also, the 
effects of scouring and marine growth on the monopile are not considered. This section discusses the modelling approach of loads followed in the present work.

\section{Aerodynamic Loads}

NREL's FAST (Jonkman and Buhl, 2005) code is used to generate the time series of aerodynamic loading at the hub of the OWT, by employing the blade element momentum theory (Moriarty and Hansen, 2005). The input time history of wind velocity for FAST is realized by means of NREL's TurbSim, which is a stochastic, full-field turbulent wind simulator (Jonkman, 2009). In TurbSim, wind speed vectors with three components on a 2-D grid enveloping the entire rotor-plane are generated through a statistical model. Each grid point represents the summation of the mean wind speed and the fluctuating component or turbulence (Bush, 2009). The normal turbulence model is used to relate the standard deviation of turbulence to the hub-height wind speed. The turbulence intensity for the analysis was taken as 0.1 . The Kaimal spectrum (Kaimal et al., 1972) is used to specify the power spectral density of the turbulence and the variation of wind speed along the vertical is represented by means of a power law profile, with the value of exponent as 0.14 (IEC, 2009).

\section{Hydrodynamic Loads}

Both FAST and USFOS make use of the Morison equation (Chakrabarti, 2005) to determine the wave loading on the monopile. Here, the total force is assumed to have a drag component as well as an inertia component, due to the fluid velocity and acceleration, respectively. According to the Morison equation, the hydrodynamic force acting per unit length on a cylindrical pile is given by: $d F=\frac{1}{2} \rho C_{D}|u| u+\rho C_{M} \frac{\pi D^{2}}{4} u$, where $\rho$ stands for the mass density of water, $D$ is the diameter of the cylindrical monopile and $u$ is the water particle velocity in the horizontal direction. The upper dot indicates acceleration. $C_{D}$ and $C_{M}$ represent the non-dimensional drag and mass coefficients. 
The suitability of the Morison equation to model wave-structure interaction for

287

288

289

290

291

292

294

295

296

297

298

299

300

301

302

303

304

305

306

307

308

monopiles in shallow water depths may be ascertained by comparison with the limits specified in Chakrabarti (2005). The wavelength $(L)$ in shallow water is determined using a suitable formula, such as Hunt's Padè approximation (Young, 1999). For the operating seastate, this corresponds to a wavelength of $121 \mathrm{~m}$. Thus, $\pi D / L<0.5$, where ' $D$ ' is the diameter of the monopile. This confirms the validity of the Morison's equation for the monopile considered in the present study, under shallow water conditions.

Irregular, long-crested waves are generated using the Joint North Sea Wave Project (JONSWAP) spectrum, recommended for use in the Indian coastal waters, by Kumar and Kumar (2008). JONSWAP spectrum takes into account the growth of waves over a limited fetch and wave attenuation in shallow water. A peakedness parameter of 3.3 is used. Irregular waves give a realistic picture of ultimate limit state analysis and are generated through Fast Fourier Transform of the wave spectrum (SINTEF Group, 2001). This is done using the constant area discretization method of the wave spectrum where the area under the spectrum is constant for each discretization (Saha et al. 2011). A finite number of discrete wave components are obtained, each component represented in terms of a harmonic wave with given amplitude, angular frequency, and random phase angle. The sea surface elevation is obtained by the superposition of all harmonic components using Rice's formula, i.e., $X(t)=\sum_{i=0}^{N-1} \sqrt{2 S\left(\omega_{i}\right) \Delta \omega} \cos \left(\omega_{i} t-\psi_{i}\right)$. Here, $\sqrt{2 S\left(\omega_{i}\right) \Delta \omega_{i}}$ is the deterministic wave amplitude, $S\left(\omega_{i}\right)$ is the spectrum studied, $\Delta \omega$ is the angular frequency discretization and $\psi_{i}$ refers to the random phase. Based on Abhinav and Saha (2015), a value of 300 frequencies is used for discretization of the wave spectrum.

Combining Loads for Aerodynamic and Hydrodynamic Analysis 

aero-hydro analysis can simulate the OWT responses accurately if the natural period of the structure is small when compared to the predominant wind and wave periods. OWT simulation programs like FAST are often crippled by the lack of a geotechnical component. In FAST, the OWT is considered to be fixed at the mudline and subjected to wind and wave loading. On the other hand FE codes like USFOS have both hydrodynamic and geotechnical capabilities. Therefore, a complete aerodynamic-hydrodynamic-geotechnical analysis of an OWT involves a suitable coupling between the two codes. The present work makes use of a coupling (Passon and Branner, 2013) of aerodynamic and hydrodynamic loads to simulate the response of the monopile supported OWT. This procedure illustrated in Figure 3a, involves two steps: (a) coupled aerodynamic-hydrodynamic analysis in FAST, by incorporating an equivalent foundation model (as explained in the next section) to generate time series of hubheight loads with components in all 6 (3 forces and 3 moments) directions and (b) application of these aerodynamic time series as external loads at the tower-top, in the USFOS model (including pile-soil interaction), along with the wave loading.

\section{Derivation of Apparent Fixity Model}

As mentioned above, in FAST the monopile is fixed at the mudline. However, the influence of SSI can be incorporated in FAST by making use of the apparent fixity or coupled springs models (Passon, 2006). It is seen that flexible foundation (i.e. SSI) models when employed in FAST, results in the prediction of higher extreme loads than the fixed base model (Bush and Manuel, 2009). The present study makes use of the apparent fixity (AF) model to include the influence of SSI in FAST, as explained below.

The AF model replaces the pile-soil system with a fictitious cantilever of equivalent stiffness. The depth of this cantilever below the mudline, where it would produce the same deflection and rotation at the mudline as the true pile-soil system under similar mudline 
moment and shear force, is called the AF depth. Now, the monopile in FAST is extended beyond the mudline by this AF depth, as shown in Figure 3a. The properties of the fictitious cantilever (i.e. AF depth and flexural rigidity) can be derived by any lateral pile analysis program such as LPILE or USFOS (which is used in the present study). The AF depth is derived as illustrated in Figure $3 \mathrm{~b}$ and the procedure is briefly outlined as follows (Bush and Manuel, 2009):

- Mudline shear and moment values are required for generating the AF properties. These values may be obtained by an initial analysis in FAST, where the monopile is fixed at the mudline, as shown in Step 1 of Figure 3b. The shear force $(F)$ and overturning moment $(\mathrm{M})$ pair at the mudline, corresponding to the extreme value is selected.

- $\quad$ This F-M pair is now used to determine the mudline displacement $(w)$ and rotation $(\theta)$ of a monopile of true dimensions (penetration depth is assumed as 6 times the diameter, D), embedded in the actual soil, with any program with capability for lateral SSI analysis, such as USFOS or LPILE. This is illustrated in Step 2 of Figure $3 b$.

- From the displacement and rotation, the AF properties can be calculated using $349 \quad w=\frac{F L^{3}}{3 E I}+\frac{M L^{2}}{2 E I} ; \quad \theta=\frac{F L^{2}}{2 E I}+\frac{M L}{E I}$, where $E I$ is the flexural rigidity and $L$, the AF depth.

- The whole process is now repeated for 50 realizations of TurbSim generated random wind fields, corresponding to a given sea-state and wind speed. The high number of simulations is intended to reduce the uncertainty in load prediction. The mean value of AF properties are computed and further analyses in FAST are now done by including the AF depth and flexural rigidity in the monopile model (Step 3 of Figure 3b).

Table 5 presents the AF length for a $6 \mathrm{~m}$ diameter monopile with an embedment depth of 
conditions. The layered soil is observed to afford the least resistance to lateral loading and consequently, has a higher value of AF length.

Being a random process, Table 6 compares the ensemble average statistics of the foreaft tower bending moment (FATBM) at mudline for the fixed base and AF models across 50 Monte Carlo sample wind fields. Two hub-height wind speeds are considered, $V_{W}=12 \mathrm{~m} / \mathrm{s}$ and $V_{W}=22 \mathrm{~m} / \mathrm{s}$, as mentioned in the previous sections.

From Table 6, it can be observed that the variation in the maximum FATBM values at the mudline depends on the sea-state and wind speed. The introduction of an equivalent foundation model increases the overall flexibility of the OWT system. However, the length of the OWT system including the tower, transition piece and pile is greater for the OWT with soil than that of fixed configuration and therefore the bending moment values are larger. The FATBM values for the met-ocean condition near cut-out wind speed are expectedly lower when compared to the operational one, due to the influence of the pitch control in OWT at higher wind speeds. Above the rated wind speed (11.4 m/s for the NREL 5MW OWT), the constant rated power is maintained by pitching of the blades (i.e. by rotating them about their longitudinal axes), such that there is a reduction in the amount of wind intercepted by the blades. This will in effect reduce the structural loads and thus the FATBM at higher wind speeds. Figure 4 show the convergence of skewness and kurtosis for the mudline FATBM for the two met-ocean conditions. It is observed that the values converge within $30-40$ realizations/seeds, indicating the number of simulations required to eliminate the statistical uncertainty. This also further reiterates the fact that 50 trials of FAST simulations used for calculating during AF model are sufficient. The results also show that the skewness and kurtosis vary widely for different soil types. For example, a higher kurtosis refers to larger short term extreme loads as can be seen for operational sea states. 


\section{Results and Discussion}

This section covers the results from the dynamic analysis of a monopile supported OWT in varying soil conditions under random wind and wave loads. For example, the reported nodal displacement is obtained by ensemble average of the corresponding maxima of displacement time series across 50 Monte Carlo simulations. All the dynamic analyses plots indicate the ensemble average response of the OWT structure.

\section{Check for Natural Frequency}

An OWT has to be checked for safety with respect to resonance, which otherwise would result in escalated structural response and hence damage. The natural frequency of the OWT structure should not coincide with any of the forcing frequencies (wind, wave and current). In addition to low frequency wind and wave loads, a three-bladed wind turbine is excited at $1 \mathrm{P}$ and 3P frequencies. Here, $\mathrm{P}$ stands for the rotor speed. 3P is termed as the rotor blade pass frequency (van der Tempel and Molenaar, 2002). When compared to 1P, turbines are heavily excited at 3P, from impulses generated when the blades pass the tower OWTs can be sited within three regimes when considering the natural frequency (LeBlanc, 2009):

- The natural frequency lies in between the maximum predominant wind and wave frequency and 1P. Such a design, called 'soft-soft', requires smaller structural dimensions and is hence cheaper. However, they are highly flexible and susceptible to fatigue failures.

- The natural frequency lies in between $1 \mathrm{P}$ and $3 \mathrm{P}$ values. Monopiles are usually designed to fall in this 'soft-stiff' region, with regard to economic and flexibility considerations.

- The natural frequency is above 3P frequency. The OWT structure is now termed as 'stiffstiff. These structures are too rigid and expensive due to their larger dimensions. 
In the present study, USFOS is used to determine the natural frequency of the monopile

407

408

409

410

411

412

413

414

415 supported OWT using the Lanczos algorithm. The RNA is modelled as a point mass at the top of the tower. The first natural frequency was found to fall in the 'soft-stiff' region, for the NREL 5MW OWT, in all the soil conditions considered. The OWT supported in mixedsandy-clayey soil showed a marginal reduction of $4 \%$ when compared with the uniform soil profiles. These values are $15-20 \%$ less than those of an OWT assumed to be fixed at the base (i.e., where SSI is ignored). It may be noted that ignoring the SSI in softer soils could result in increased periods of vibration wherein, the fundamental natural frequency would dip into the critical $1 \mathrm{P}$ region, resulting in resonance. These variations in natural frequencies are illustrated in Figure 5. Table 7 compares the natural frequencies corresponding to the first four modes of the OWT in different soils.

\section{Investigation of failure modes through pushover analysis}

Pushover analysis (DNV, 1999, Skallerud and Amdahl, 2009) is a tool for investigating the ultimate capacity of piles under extreme loads (Mukhopadhyay et al., 2008). They are widely used to determine the reserve strength ratio of offshore structures and to investigate the damage and probable extension of service life. Pile pushover analyses were conducted to study the failure mechanism of the OWT foundation under extreme loads. Large diameter OWT monopiles show rigid body behaviour and fail by rotation (Augustensen et al., 2009).

The pushover analysis is conducted in two steps: first, the time-invariant dead loads (gravity) on the OWT are applied to their actual values. This is followed by gradual increase of the environmental (lateral) loads (wind and wave), till the eventual collapse of the OWT. In the present study, pushover analyses are performed with respect a combination of wind and wave loads for the near-cut-out sea-state i.e., $V_{W}=22 \mathrm{~m} / \mathrm{s}, H_{S}=10 \mathrm{~m}$ and $T_{P}=14 \mathrm{~s}$. The 
wind load at the top of the tower is represented by a value of $650 \mathrm{MN}$, which is the ensemble maximum across 50 realizations for the corresponding met-ocean state.

Figure 6a shows the pushover curves for the different soils up to the collapse load, which can be defined as the highest point in the curve before it shows the negative trend. The ultimate capacity of layered soil and medium dense sand is found to be higher than that of stiff clay. Also, the stiffer soils - medium sand and stiff clay- show similar trends in the initial portion of the curves. Corresponding to the collapse load, the displacement profiles along the piles (subsoil part) for the different soil configurations are also plotted in Figure 6b. It is observed that piles in stiffer soils fail through bending and the formation of plastic hinges, whereas, those in softer soils (layered soil) show rigid body behaviour and fails through a rotation. Here, the well-known 'toe-kick' phenomenon is observed.

Also, an attempt is made to understand the contribution of only wave loads towards collapse. Therefore, pushover analysis with respect to wave loading alone has been performed and the results are plotted in Figures $7 \mathrm{a}$ and $7 \mathrm{~b}$. The ultimate strength behaviour of the monopile structure is relatively unchanged when the wind load is removed, as observed in Figures $7 \mathrm{a}$ and $7 \mathrm{~b}$. As a result of the reduction in applied loading, collapse occurs at a higher load level. For medium dense sand and stiff clay, the displacement profile along the pile (Figure 7b) shows a similar trend to the combined wind and wave case. However, in the case of layered soil, the rotation is more pronounced.

In Figure 6a, pushover curve of the monopile in layered soil shows continuous increase in response with load. In pushover analysis, the loads are incremented gradually and the structure reacts by the formation of plastic hinges. The gradual increase in load continues up to point A (refer Figure 6a) and then there is a sudden failure in the OWT structure caused by the simultaneous yielding of the tower (at the interface between the transition piece and the tower caused by the wind loads) and the pile. This appears as a jump (from A to B) in the 
pushover curve. A similar phenomenon is observed for medium dense sand, in the analysis with only wave loads (Figure 7a). However, in this case the pile elements alone yield as only the wave loads are considered (wind loads are absent from the top of the tower).

\section{Influence of soil type} was studied with respect to the three different soil types specified in the earlier sections. The analysis was based on the operational wind speed and sea-state. The displacement profiles for a monopile of $36 \mathrm{~m}$ depth in various soil conditions are presented in Figure 8. layers. It may be observed from Table 2 that the layered soil has lower stiffness values in the upper layers when compared to the sand and clay profiles. This stiffness variation is reflected in the displacement profiles; the tower-top displacement for the layered soil exceeds that of stiff clay and medium dense sand by $10 \%$ and $13 \%$, respectively. Figure 8 also shows the lateral displacement along the pile from the mudline. The variation in response and resistance of the mixed soil with low stiffness is distinctly visible along the upper layers. The mudline displacement of the pile in the mixed layer is double that of the pile in the sandy soil.

\section{Influence of pile penetration depth and pile diameter}

Three different penetration depths - 5D, 6D and 7D, where $\mathrm{D}$ is the diameter of the monopile, were considered for the operational sea-state. The results are plotted in Figure 9(a). The displacement profiles for the stiffer soils (stiff clay and medium dense sand) remain relatively constant, even with a variation in pile penetration depth. This is indicative of the suitability of a lower pile penetration depth $(30 \mathrm{~m})$ for safe operation of the OWT. However, in the case of the softer, mixed soil, a reduction in pile depth from $6 \mathrm{D}$ to $5 \mathrm{D}$ is accompanied by an increase in tower-top displacement by $9 \%$. 

sea-state. The pile penetration depth was kept constant at $36 \mathrm{~m}$. The results are shown in Figure 9(b). The change in pile diameter directly influences the foundation stiffness and the response is expected to reduce with an increase in pile diameter. As the pile diameter increases from $5 \mathrm{~m}$ to $7 \mathrm{~m}$, tower-top lateral displacement reduces by $40 \%$ for the stiffer soils and by $65 \%$ for layered soil.

\section{Influence of met-ocean condition}

In addition to the operating conditions, a loading scenario near cut-out wind speed of the turbine is also considered. As mentioned above, this corresponds to a met-ocean condition defined by $H_{S}=10 \mathrm{~m}, T_{P}=14 \mathrm{~s}$ and $V_{w}=22 \mathrm{~m} / \mathrm{s}$. At higher wind speeds, the control systems of the OWT comes into play and these results in reduced wind loads. As shown in Figure 9(c), tower-top lateral response at the near cut-out met-ocean state is less than that at the operational one, in spite of the greater value of significant wave height. This may be attributed to the hub-height load reduction from the wind turbine control actions.

Figure 10 shows the ensemble statistical parameters (mean and maximum) for lateral deflection at two important design levels in the structure - mudline and tower top. Bar diagrams are plotted for both sea states and three soil profiles considered. Such charts may be used during the initial stage of design of an OWT, to get an idea of the maximum response under particular soil and loading conditions.

\section{Sensitivity analysis}

Sensitivity analyses for sand and stiff clay have been performed to investigate the influence of variation of properties within a specific soil configuration on the response of the OWT structure. According to the API-RP-2A-WSD (2014), the stiffness of sandy soil is largely 
influenced by the angle of internal friction. Figure 11 (a) shows the variation in the pile head

507 displacement for both operational and near cut-out met-ocean conditions, with increasing angle of internal friction. As mentioned in the previous sections, the ensemble mean of maximum values across a sample size of 50 random wind and wave fields are plotted. Both 510 load-cases show similar trends, with a sudden reduction in response once the soil crosses from loose to medium dense (at $30^{\circ}$ ). Further increase in the angle of internal friction is accompanied by a gradual reduction in the pile head displacement as the soil becomes dense 513 (beyond $36^{\circ}$ ).

514 Clay is considered to be stiff for values of undrained shear strength greater than $100 \mathrm{kPa}$ 515 (Reese and van Impe, 2011). Figure 11 (b) shows the influence of increasing shear strength values for stiff clay on the pile head lateral deflection. Stiff clay is observed to show a mostly linear reduction in response with increasing undrained shear strength. For both soils, displacement at the near cut-out met-ocean condition is greater than that at the operational one, due to the higher magnitude of wave loads imposed on the structure.

\section{Conclusions}

The present work undertakes a coupled analysis including soil structure interaction (SSI), on a monopile supported NREL benchmark 5MW OWT in shallow waters. The stochastic aerodynamic-hydrodynamic analysis procedure is followed within a finite element framework. Three different soil types are studied - layered soil, medium dense sand and stiff clay. SSI is incorporated by means of nonlinear soil-springs as per API-RP-2A-WSD (2014) recommendations. One may draw the following conclusions on the basis of this work: 1. Ignoring SSI could result in overestimation of the natural frequency of the OWT structure, thereby allowing the possibility of resonant response as there are different types of loading frequencies due to wind and wave along with their combinations. 
531 2. The effect of stiffness in governing the lateral response of monopile OWTs under 532 dynamic loading has been established.

533 3. Seed convergence studies give an idea of the number of simulations required to eliminate 534 the statistical uncertainty. Using the ensemble statistics, the mean, standard deviation and 535 maxima, one can obtain characteristic values for probabilistic design.

536 4. Stiffer soils show negligible variation in response to change in the pile penetration depths 537 in the range $5 \mathrm{D} \rightarrow 7 \mathrm{D}$.

538 5. Pushover analysis of piles using quasi-static mudline loads indicates that large diameter 539 monopiles show rigid body mechanism.

540 6. Reduction in OWT lateral response brought about by an increase in pile diameter was 541 more prominent in the softer, layered soil.

542 7. OWT control actions dictate the response in the near cut-out met-ocean condition, 543 irrespective of the soil conditions studied.

544 8. The OWT response results from nonlinear finite element program USFOS (SINTEF 545 Group, 2001) have been validated using SESAM Wind (DNV GL, 2016), another 546 commercial program for the time domain analysis of fixed bottom OWT structures.

\section{Acknowledgements}

549 The authors would like to thank Dr. Tore Holmas of www.usfos.no and Dr Jason Jonkman of 550 the NREL, for their help with USFOS and FAST, respectively. The authors would also like to 551 gratefully acknowledge the financial support given by the Earth Systems Science Organization, Ministry of Earth Sciences, and Government of India through National Institute of Ocean Technology to conduct part of the research. The authors also thank Prof S.

554 Bhattaacharya of Chair in Geomechanics, University of Surrey for his patient reading and 555 insightful comments. 


\section{References}

1. Abhinav, K.A. and Saha, N. (2015)."Coupled hydrodynamic and geotechnical analysis of 560 jacket offshore wind turbine, "Soil Dyn. Earthq. Eng.,73, 66-79.

2. Abhinav, K.A., Saha, N. (2017) "Stochastic response of jacket supported offshore wind turbines for varying soil parameters", Renewable Energy, 101, pp. 550-564.

563

3. ABS (American Bureau of Shipping). (2011). "Design Standards for Offshore Wind 564 Farms", USA.

565

4. Achmus, M. and Abdel-Rahman, K. (2012). "Design of Piles for Offshore Wind Energy 566 Foundations with Respect to Horizontal Loading,"Proc.,22nd International Offshore and Polar Engineering Conf., ISOPE, Rhodes, Greece, 143-150.

5. Aranya L., Bhattacharya, S., Macdonald J, Hogan S.J. (2017) "Design of monopiles for offshore wind turbines in 10 steps." Soil Dynamics and Earthquake Engineering, Vol-92, pp.126-152

6. Bhattacharya, S., Cox, J.A., Lombardi, D., and Wood, D. M. (2013), "Dynamics of offshore wind turbines supported on two foundations", Proceedings of the Institution of Civil Engineers - Geotechnical Engineering, Vol-166(GE2), pp. 159-169.

7. Bouzid, D. A, Bhattacharya, S. and Dash, S.R (2013) "Winkler Springs (p-y curves) for 575 pile design from stress-strain of soils: FE assessment of scaling coefficients using the 576 Mobilized Strength Design concept”, Geomechanics and Engineering, Vol-5 (5), pp. 379-399 8. API-RP2A-WSD (2007). "Recommended Practice for Planning, Designing and Institute, USA. 
9. API-RP-2GEO (2011). "Geotechnical and Foundation Design Considerations,",

581

582

583

584

585

586

587

588

589

590

591

592

593

594

595

596

597

598

599

600

601

602

American Petroleum Institute, USA.

10. Augustesen, A.H., Brødbæk,K.T.,Møller, M.,Sørensen, S.P.H., Ibsen,L.B., Pedersen, T.S. and Andersen, L. (2009)."Numerical Modelling of Large-Diameter Steel Piles at Horns Rev,"Proc. 12th Int. Conf. on Civil, Struc and Environmental Engg Computing, Scotland.

11. Barltrop, N.D.P., and Adams, A.J. (1977).Dynamics of Fixed Marine Structures, Butterworth-Heinemann Ltd., Oxford, UK.

12. Bazeos, N., Hatzigeorgiou, G.D., Hondros, I.D., Karamaneas, H., Karabalis, D.L. and Beskos, D.E. (2002). "Static, seismic and stability analysis of a prototype wind turbine steel tower," Eng.Struct., 24, 1015-1025.

13. Bilgili, M., Yasar, A. and Simsek, E. (2011)."Offshore wind power development in Europe and its comparison with onshore counterpart, "Renew.Sust. Energ. Rev., 15, 905- 915.

14. Bisoi, S. and Haldar, S. (2014), "Dynamic analysis of offshore wind turbine in clay considering soil-monopile-tower interaction, "Soil Dyn. Earthq. Eng.,63, 19 - 35.

15. Bossanyi, EA. (2000)."Bladed for Windows - User Manual, "Garrad Hassan, UK.

16. Bush, E., and Manuel, L. (2009)."Foundation Models for Offshore Wind Turbines,"Proc. 47th AIAA Aerospace Sciences Meeting, Orlando, USA.

17. Bush, E. (2009)."A Comparison of Alternative Foundation Models for Offshore Wind Turbines and Resulting Long-Term Loads,"M.S. Thesis, University of Texas, Austin.

18. Chakrabarti, S.K. (2005).Handbook of Offshore Engineering - Volume I, Elsevier, UK.

19. Damgaard, M., Zania, V., Andersen, L.V and Ibsen, L.B. (2014)."Effects of soilstructure interaction on real time dynamic response of offshore wind turbines on monopiles, "Eng. Struct., 75, 388-401. 
603

604

605

606

607

608

609

610

611

612

613

614

615

616

617

618

619

620

621

622

623

624

625

626

627

20. DNV (1999), Ultiguide - Best Practice Guideline for Use of Non-Linear Analysis Methods in Documentation of Ultimate Limit States of Jacket Type Offshore Structures, Det Norske Veritas, Norway.

21. DNV-OS-J101 (2014). "Design of Offshore Wind Turbine Structures," Det Norske Veritas, AS, Norway.

22. DNV GL (2016), SESAM Wind User Manual - Analysis of fixed offshore wind structures (presently known as Fatigue Manager), DNV-GL-AS.

23. Gao, Z., Saha, N., Moan, T. and Amdahl, J. (2010). "Dynamic analysis of offshore fixed wind turbines under wind and wave loads using alternative computer codes,"Proc.3rd EAWE Conference, TORQUE 2010: The Science of Making Torque from Wind, Crete, Greece.

24. Gavin, K., Igoe, D. and Doherty, P. (2010)."Piles for offshore wind turbines: a state-ofthe-art review," Proc Inst Civil Eng.-Geotec., 164, 245 - 256.

25. Guanche, Y., Guanche, R., Camus, P., Mendez, F.J, and Medina, R. (2013)."A multivariate approach to estimate design loads for offshore wind turbines," Wind Energy, 16, $1091-1106$.

26. Guo, Z., Yu, L., Wang, L., Bhattacharya, S., Nikitas G. and Xing, Y. (2015) "Model Tests on the Long-Term Dynamic Performance of Offshore Wind Turbines Founded on Monopiles in Sand”, J. Offshore Mech. Arct. Eng 137(4), 041902 (11 pages),

27. IEA (Int. Energy Agency). (2013)."Technology Roadmap-Wind Energy," Paris, France.

28. IEC (International Electrotechnical Commission). (2009)."IEC 61400-3: Wind turbines Part 3: Design requirements for offshore wind turbines," IEC Publications, Geneva.

29. Jonkman, B.J. (2009)."TurbSim User's Guide v 1.50," Technical Report NREL/TP-50046198, National Renewable Energy Laboratory, Golden, CO, USA.

30. Jonkman, J.M. and Buhl, M.L. Jr. (2005), "FAST User's Guide," Technical Report NREL/EL-500-38230, National Renewable Energy Laboratory, Golden, CO, USA. 
31. Jonkman, J.M., Butterfield, S., Musial, W. and Scott, G. (2009)."Definition of a 5-MW Reference Wind Turbine for Offshore System Development," Technical Report NREL/TP500-38060, National Renewable Energy Laboratory, Golden, CO, USA.

32. Kaimal, J.C., Wyngaard, J.C., Izumi, Y., and Cote, O.R., (1972)."Spectral characteristics of surface-layer turbulence," QJ Roy. Meteor. Soc.,98, 563-589.

33. Kumar, V.S., and Kumar, K.A., (2008), "Spectral characteristics of high shallow water waves," Ocean Eng., 35, 900-911

34. Larsen, T.J. (2009). "HAWC2 - The User's Manual, version 3-8"

35. LeBlanc, C. (2009)."Design of Offshore Wind Turbine Support Structures - Selected Topics in the Field of Geotechnical Engineering," PhD thesis, Aalborg University, Denmark.

36. Lesny, K. and Wiemann, J. (2005)."Design aspects of monopiles in German offshore wind farms," Proc. Int. Symp on Frontiers in Off Geotech IS-FOG 2005, Perth, 383 - 389.

37. Li, M., Zhang, H., and Guan, H. (2011). "Study of offshore monopile behaviour due to ocean waves," Ocean Eng., 38, 1946 - 1956.

38. Moriarty, P. J., and Hansen, A.C. (2005). "AeroDyn Theory Manual," Technical Report NREL/EL-500-36881, National Renewable Energy Laboratory, Golden, CO, USA.

39. Morison, J.R., O'Brien, M.P., Johnson, J.W. and Schaaf, S.A. (1950), "The force exerted by surface waves on piles," Journal of Petroleum Technology, 2 (5), 149 - 154.

40. Mukhopadhyay, M., Choudhury, D., Phanikanth, V.S. and Reddy, G. R. (2008)."Pushover analysis of piles in stratified soil, "Proc. 14th World Conf. on Earthquake Engineering, Beijing, China.

41. Nikitas, G., Arany, L., Aingaran, S., Vimalan, J., and Bhattacharya S. (2017), "Predicting long term performance of offshore wind turbines using cyclic simple shear apparatus”, Soil Dynamics and Earthquake Engineering, 92, pp. 678-683 
42. Sivakholundu, K.M., Joseph, K.J., and Jena, B.K. (2014). "Wave Atlas of the Indian Coast," National Institute of Ocean Technology, Chennai, India

43. Passon, P. (2006)."Memorandum: Derivation and Description of the Soil-Pile-Interaction Model," IEA-Annex XXIII Subtask 2, University of Stuttgart.

44. Passon, P. and Branner, K. (2013)."Load calculation methods for offshore wind turbine foundations, "Ships and Offshore Structures., 9, 1 - 17.

45. Reese, L.C., Cox, W.R and Koop, F.D. (1975), "Field testing and analysis of laterally loaded piles in stiff clay," Proc. VIIth Annual Offshore Technology Conf., Houston, Texas, $672-690$

46. Reese, L.C. and van Impe, W.F. (2011). Single Piles and Pile Groups under Lateral Loading, CRC Press, London.

47. Saha, N., Gao, Z. and Moan T. (2011) "Sampling uncertainty of simulated stochastic waves and response process of a vertical cylinder fixed to sea-bed" Proceedings of the 8th International Conference on Structural Dynamics, EURODYN 2011 Leuven, Belgium.

48. Schaumann, P. and Boker, C. (2005)."Can jackets and tripods compete with monopiles?," Proc. of Copenhagen Offshore Wind, COW05, Copenhagen, Denmark.

49. Seidel, M., Ostermann, F., Curvers, A.P.W.M., Kuhn, M., Kaufer, D., and Boker, C. (2009)."Validation of offshore load simulations using measurement data from the DOWNVInD project," Proc. European Offshore Wind, Stockholm, Sweden.

50. SINTEF Group (2001). "USFOS Getting Started," Structural Engineering, MARINTEK.

51. Skallerud, B. and Amdahl, J. (2009), Nonlinear Analysis of Offshore Structures, Research Studies Press Ltd., England.

52. van der Tempel, J. and Molenaar, D-P (2002)."Wind Turbine Structural Dynamics - A Review of the Principles Onshore and Offshore," Wind Engg, 26, 211- 220. 
676

677

678

679

680

681

682

683

684

685

686

687

688

689

690

691

692

693

694

695

696

697

698

699

700

701

702

02

53. Wiemann J., Lesny K., and Richwien, W. (2004)."Evaluation of pile diameter effects on soil-pile stiffness,"Proc. 7th German Wind Energy Conf., Germany.

54. Young, I.R. (1999), Wind Generated Ocean Waves, Elsevier, Oxford, UK.

(n)

(1)

(n)

\section{List of Figures}

1. Conceptual and FE (USFOS) models of OWT

2. Modelling considerations used in the present study

3. Loading scheme used in the present study

4. Seed convergence study of statistics (skewness and kurtosis) for fore-aft tower bending moment for two different met-ocean scenarios

5. Forcing and natural frequencies for NREL 5MW OWT

6. Pushover analysis of monopile OWT - combined wind and wave

7. Pushover analysis of monopile OWT - combined wave only

8. Variation of OWT lateral displacement response with different soil profiles

9. Variation of lateral displacement with (a) penetration depth, (b) pile diameter under operational loading and (c) with met-ocean conditions

10. Ensemble statistics for response of OWT (LS-layered soil, MDS-medium dense soil, SC-stiff clay) ( $V_{W}=12 \mathrm{~m} / \mathrm{s}$ with $H_{S}=4 \mathrm{~m}$ and $T_{P}=10 \mathrm{~s}$ and $V_{W}=22 \mathrm{~m} / \mathrm{s}$ with $H_{S}=10 \mathrm{~m}$ and $T_{P}=14 \mathrm{~s}$ )

11. Sensitivity analysis $\left(V_{W}=12 \mathrm{~m} / \mathrm{s}\right.$ with $H_{S}=4 \mathrm{~m}$ and $T_{P}=10 \mathrm{~s}$ and $V_{W}=22 \mathrm{~m} / \mathrm{s}$ with $H_{S}=10 \mathrm{~m}$ and $T_{P}=14 \mathrm{~s}$ )

(1)

\section{List of Tables}


2. Properties of soils used for analysis

704

3. Soil profile used for validation

705

4. Apparent fixity depth for different soil types

706

5. Ensemble load statistics for FATBM at mudline

707

6. Natural frequencies and bending modes

708

7. Tower top displacement comparison

709

710

711

712

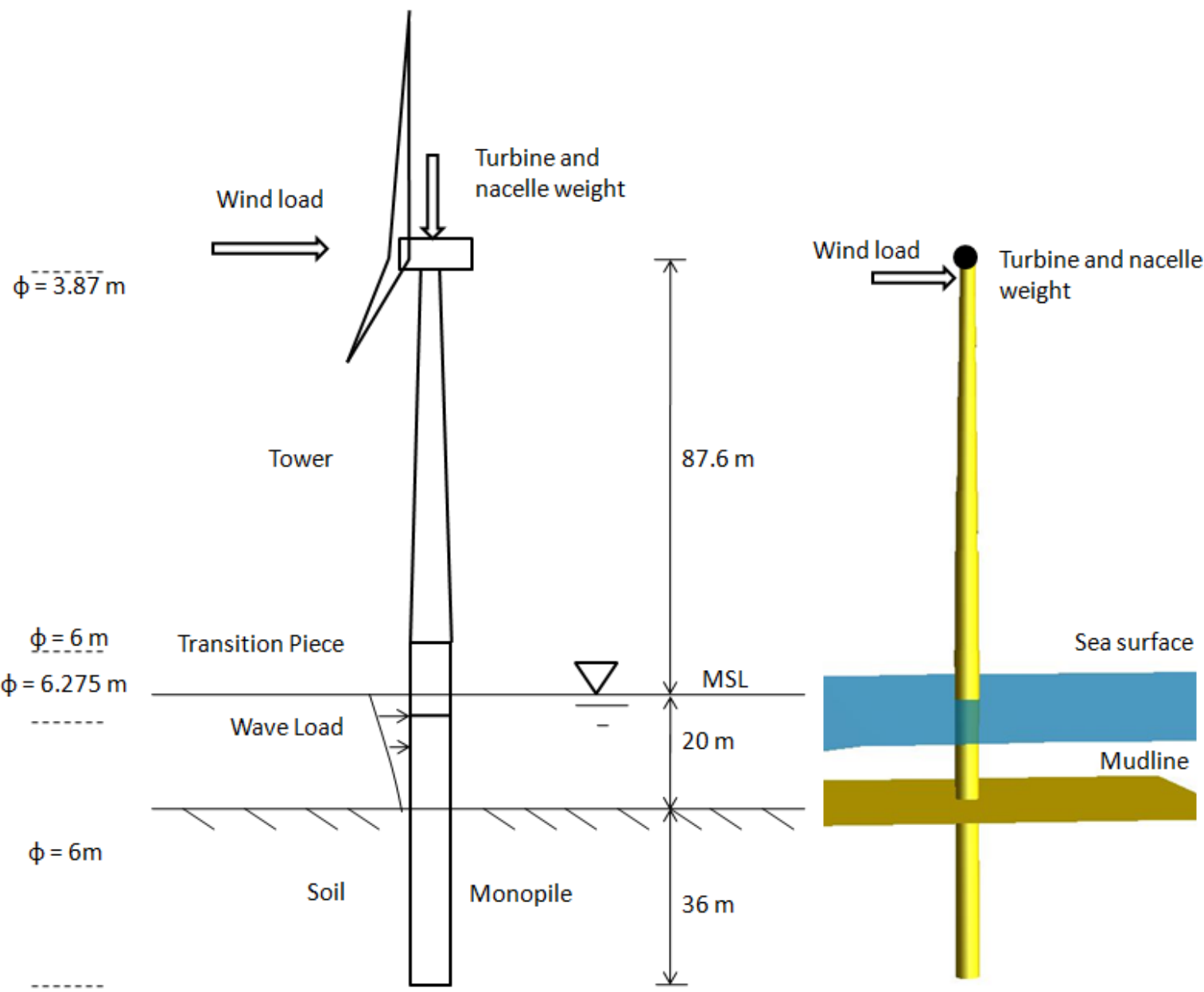

Fig. 1.Conceptual and FE (USFOS) models of OWT

714 


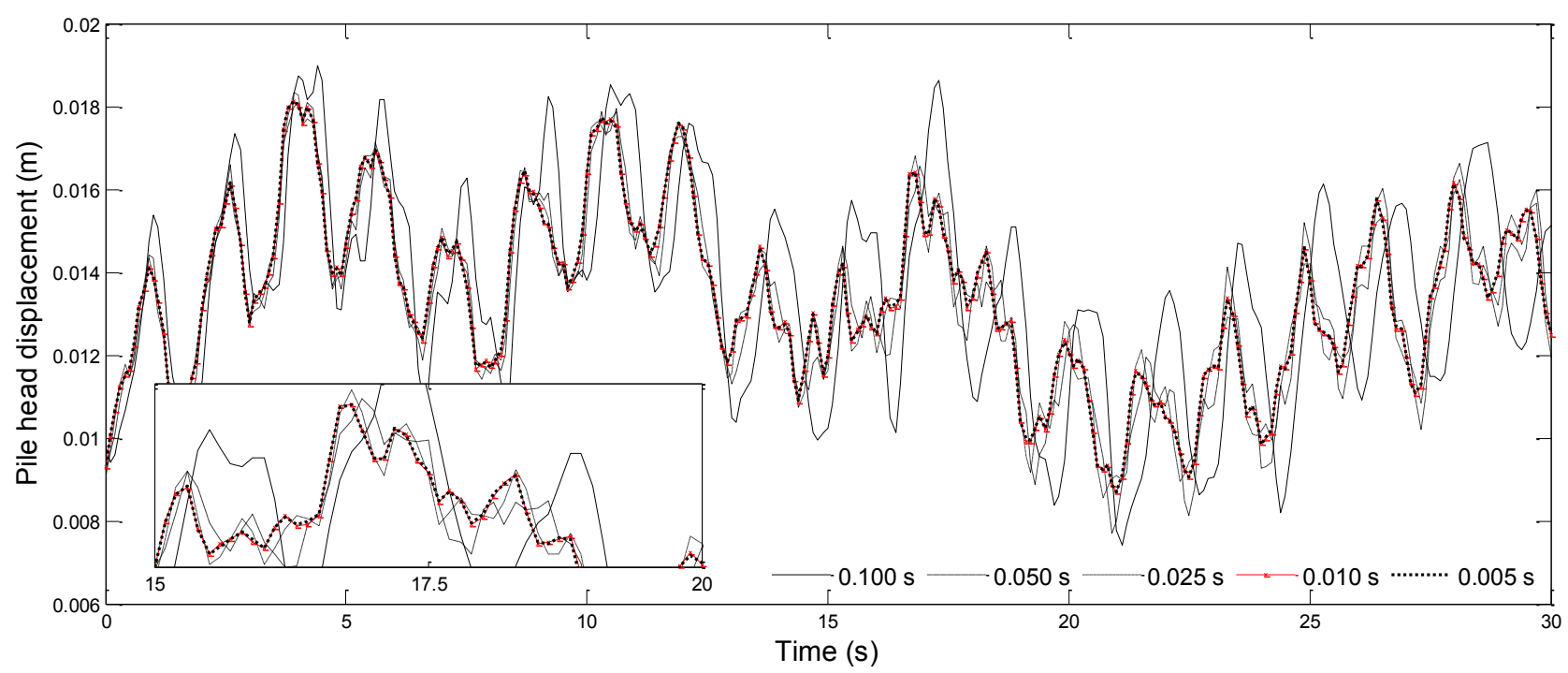

717
Fig. 2a. Time-step convergence

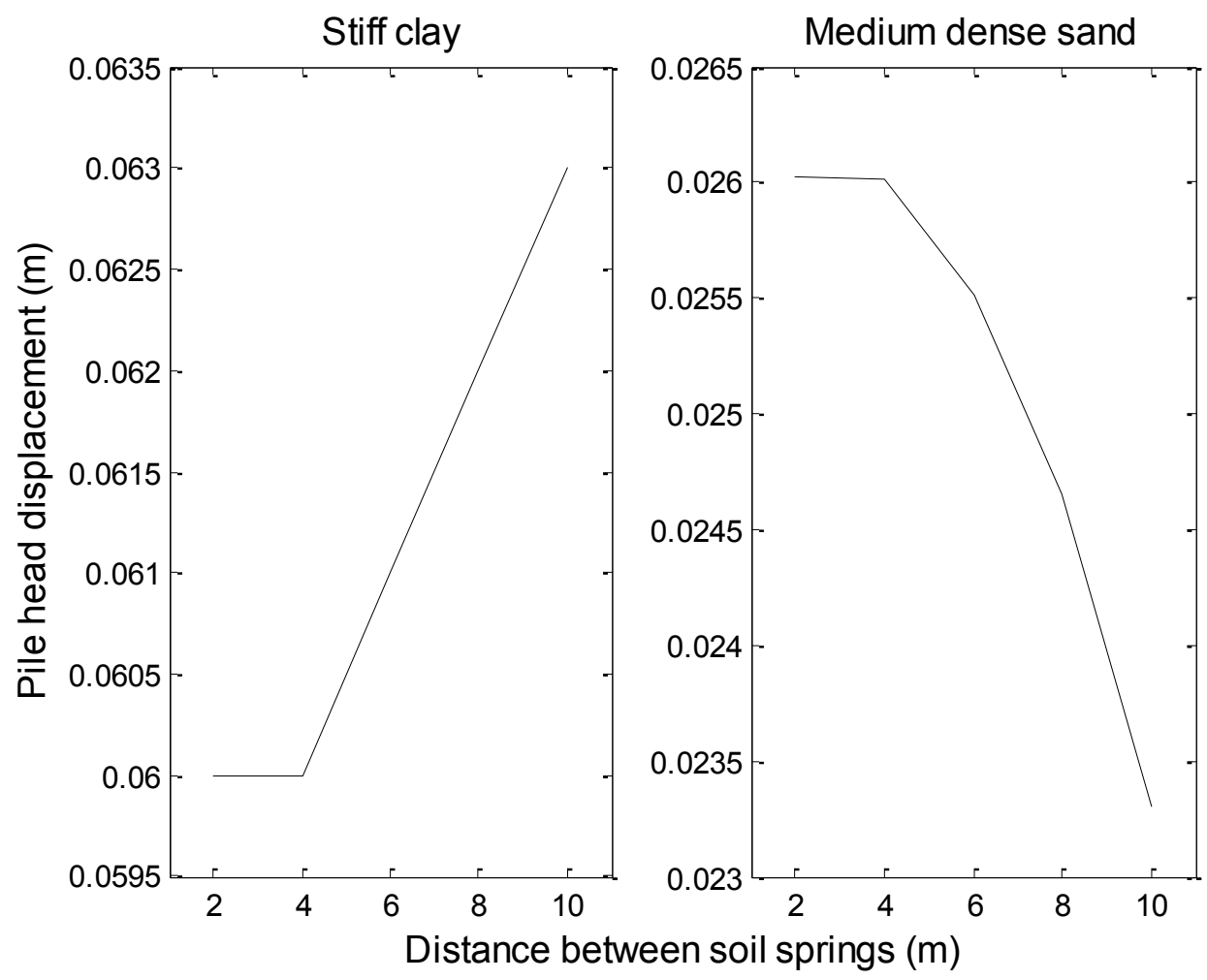

Fig. 2b. Soil-spring density convergence 


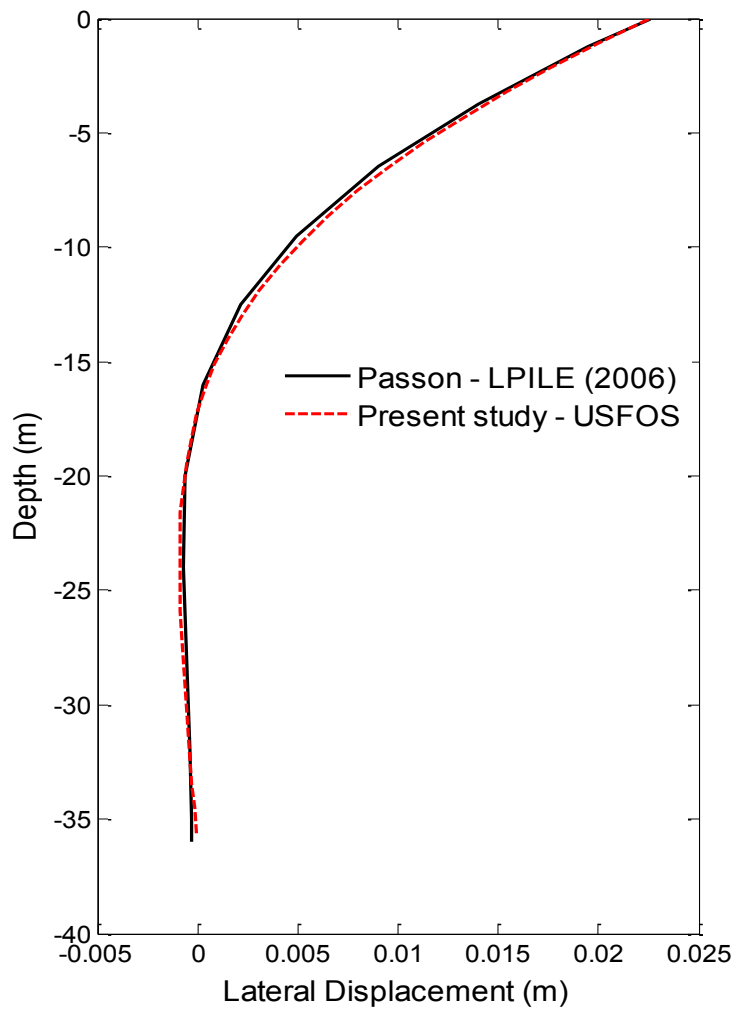

Fig. 2c. Validation of USFOS with LPILE

Fig. 2. Modelling considerations used in the present study 


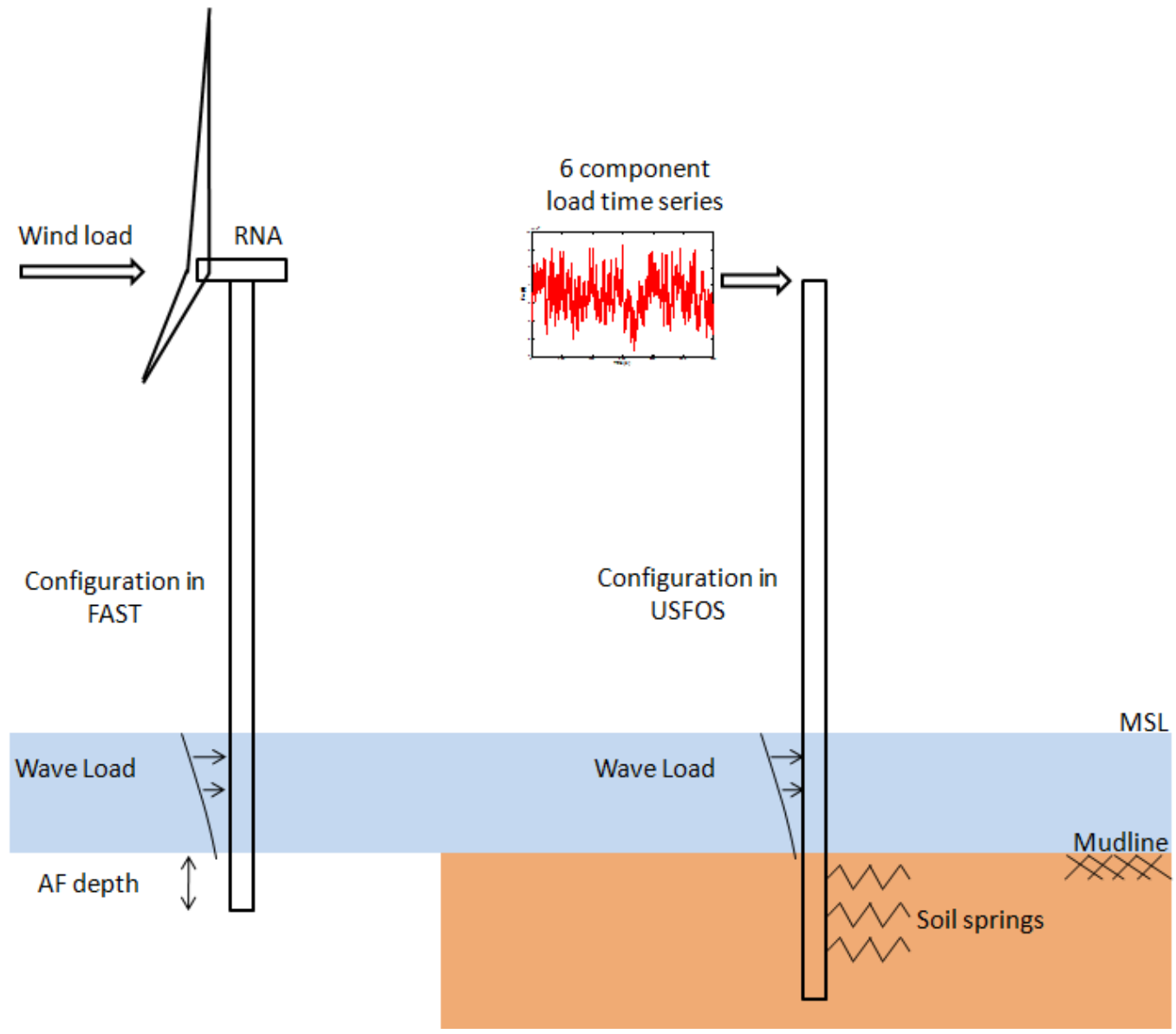

Fig. 3a. Combining loads for aerodynamic and hydrodynamic analysis

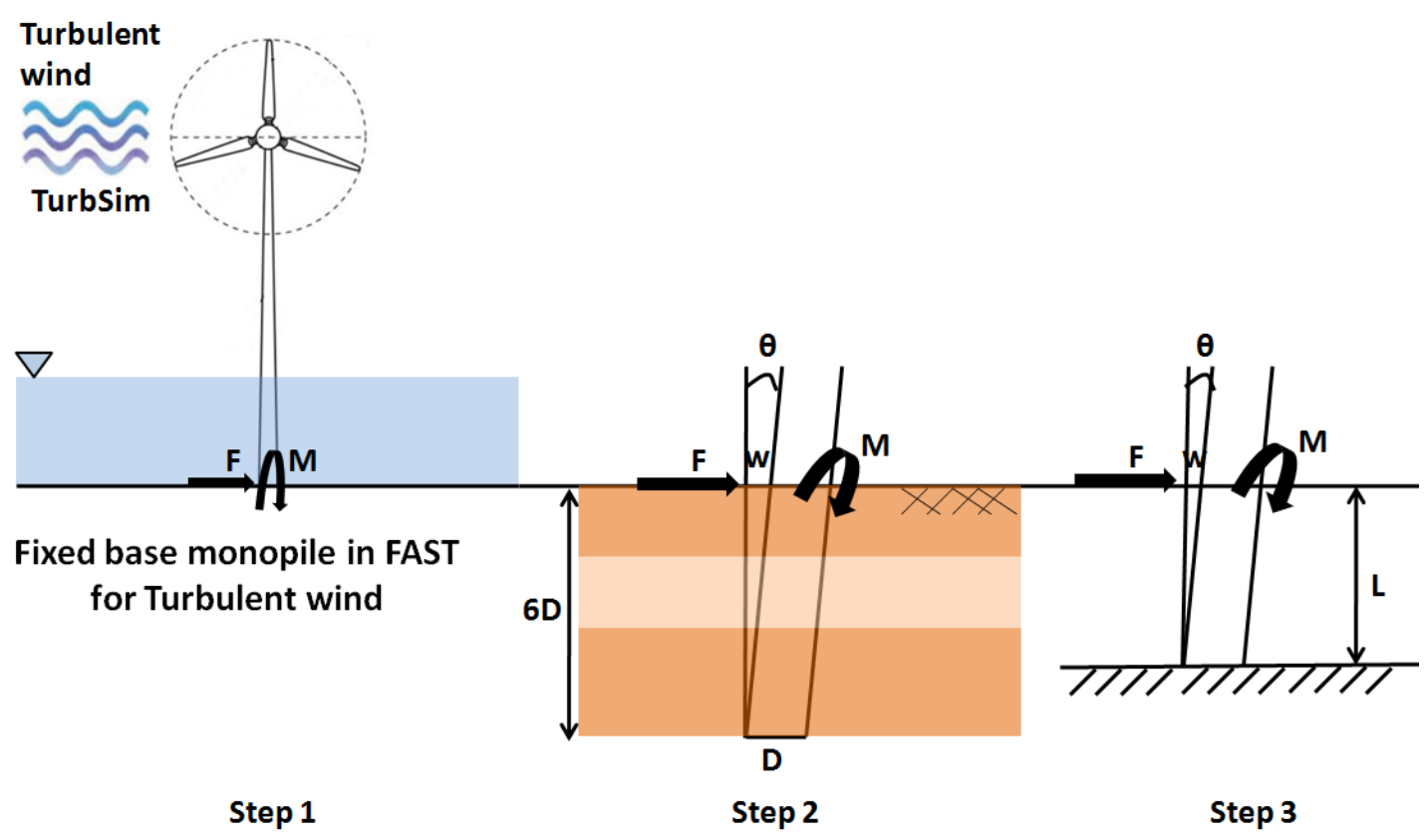

Fig. 3b. Derivation of apparent fixity model (modified from Bush (2009))

Fig. 3. Loading scheme used in the present study 


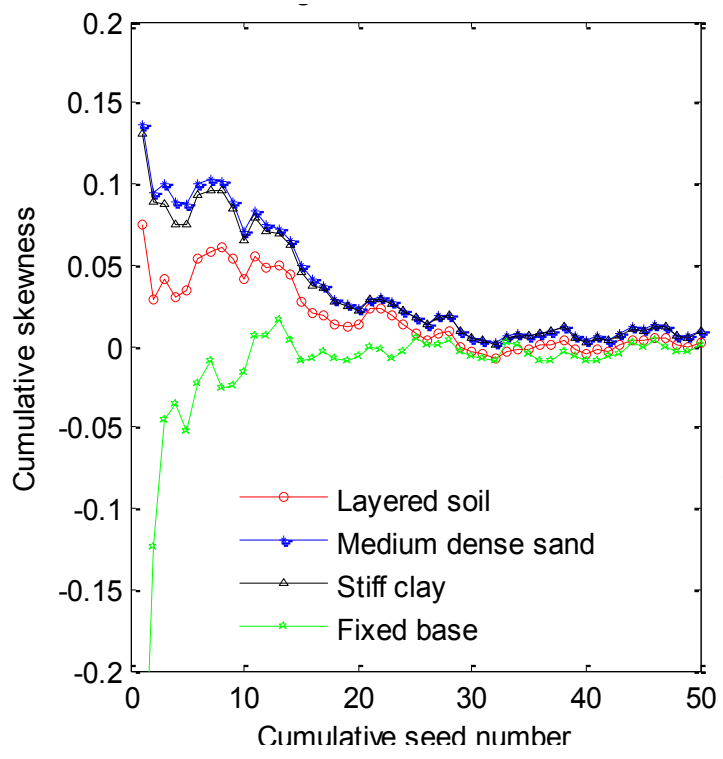

(a) operational condition -Skewness

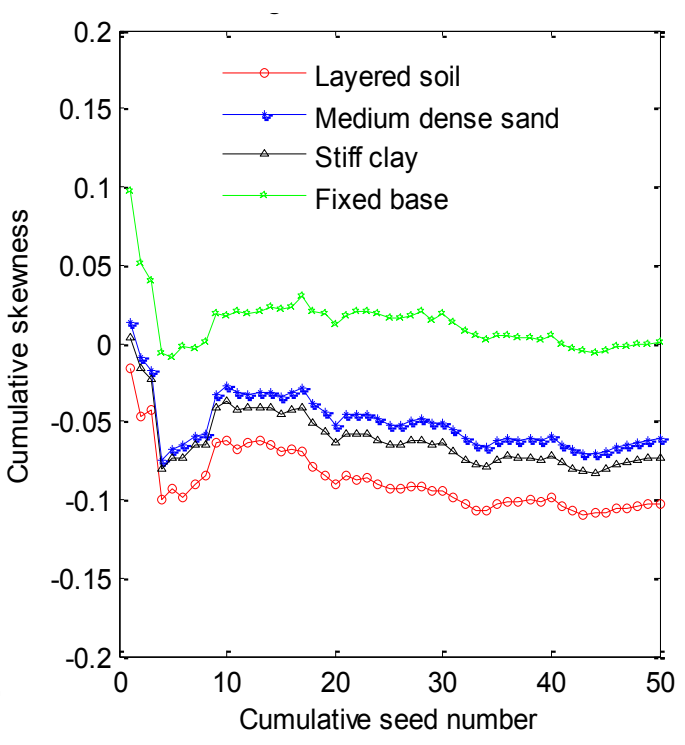

(b) near cut-out regime-Skewness

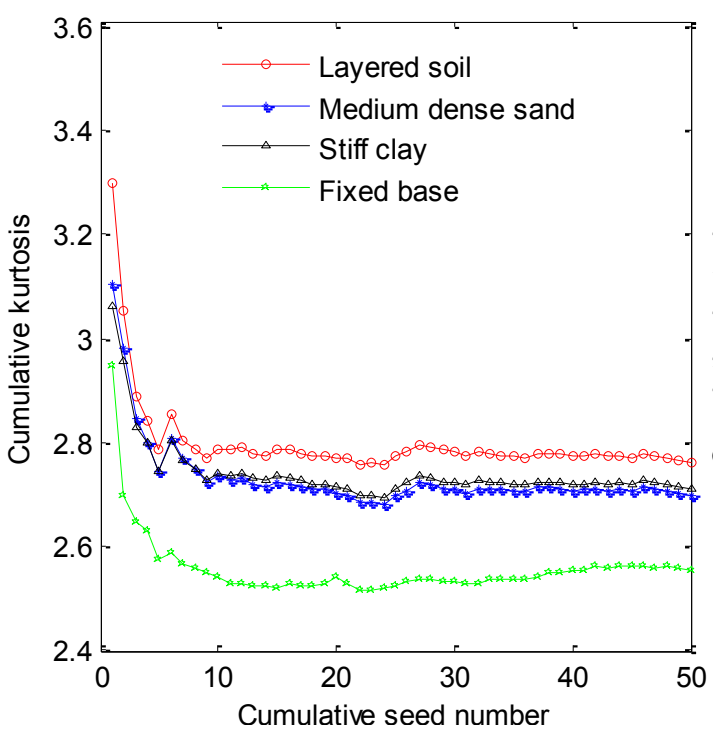

(c) operational condition -kurtosis

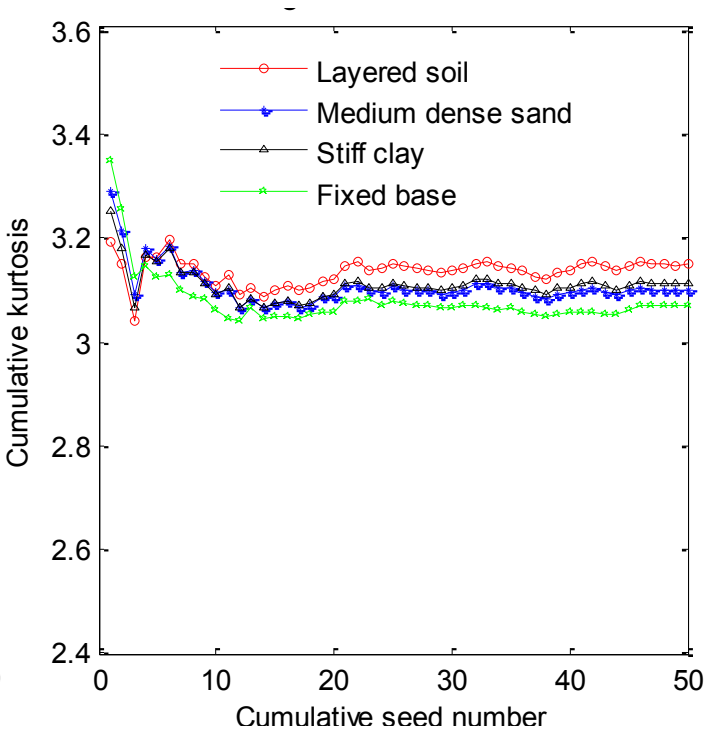

(d) near cut-out regime -kurtosis

Fig. 4. Seed convergence study of statistics (skewness and kurtosis) for fore-aft tower bending moment for two different met-ocean scenarios 


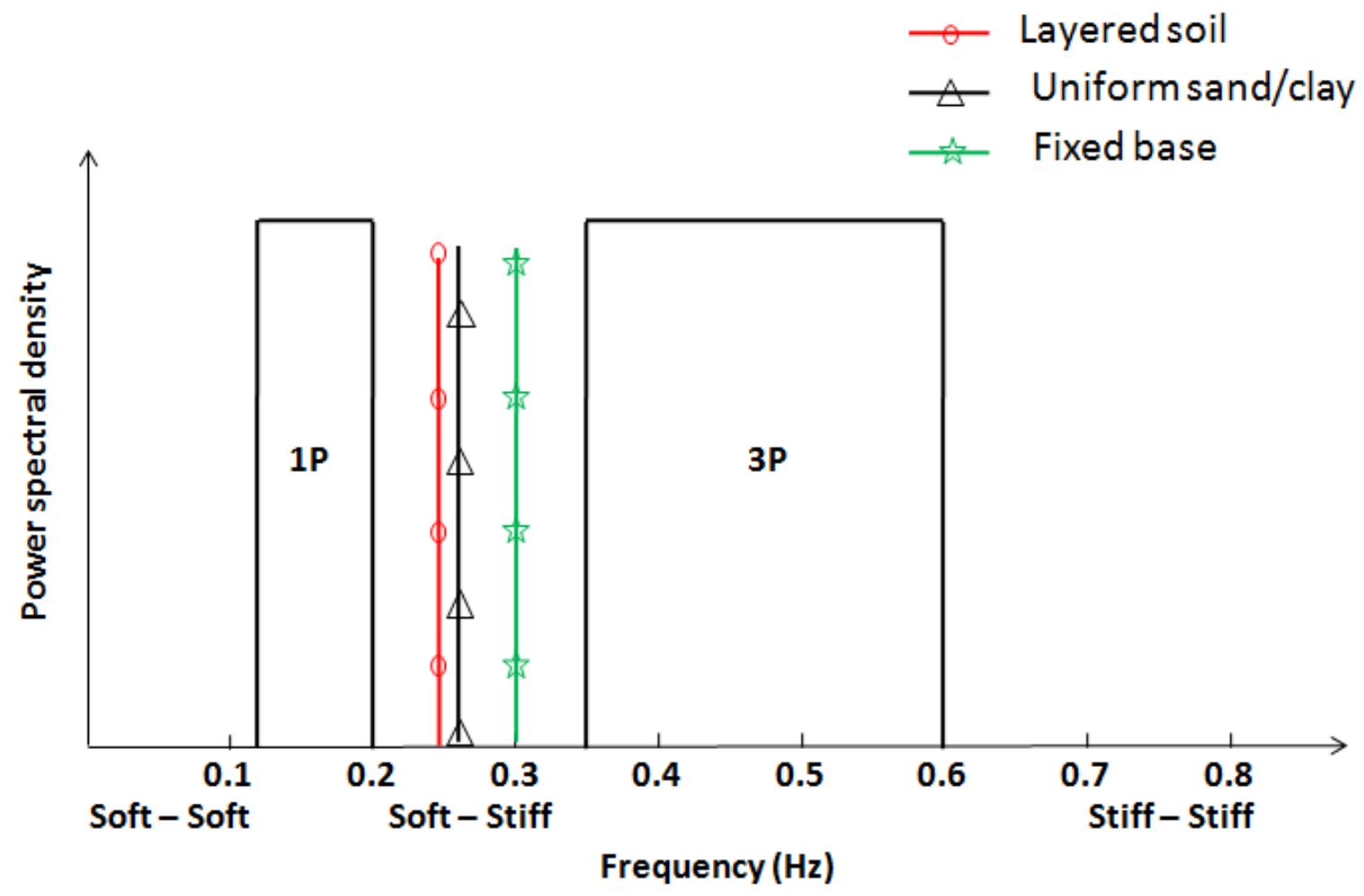

Fig. 5. Forcing and natural frequencies for NREL 5MW OWT 


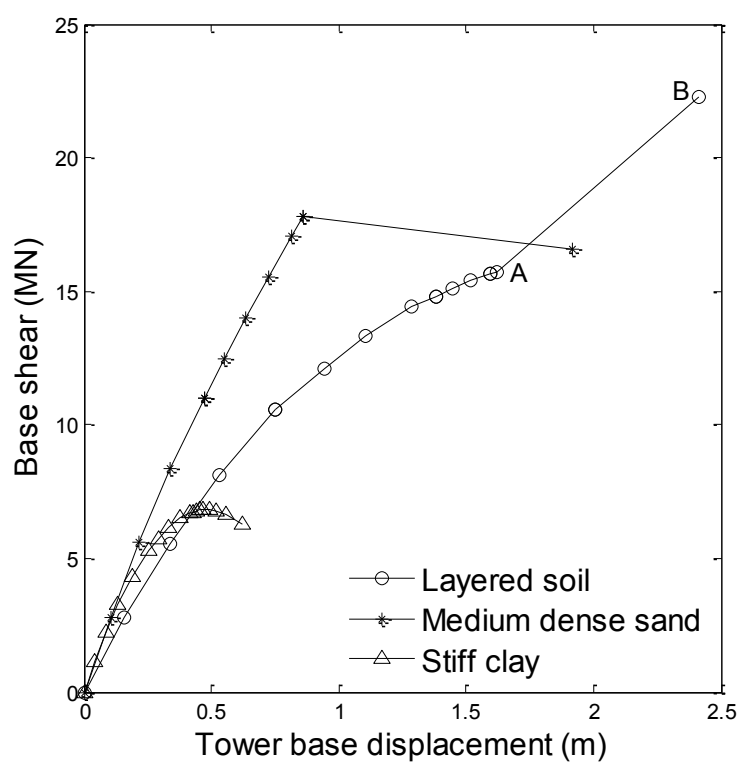

(a) Pushover response curves

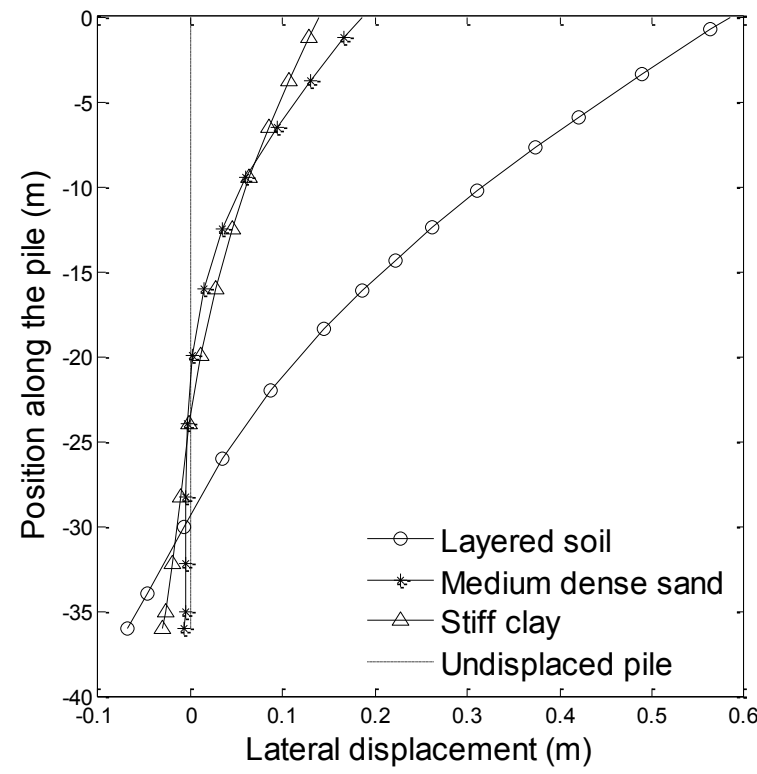

(b) Displacement profiles at collapse

Fig. 6. Pushover analysis of monopile OWT - combined wind and wave

753

754

755

756

757

758

759

760 


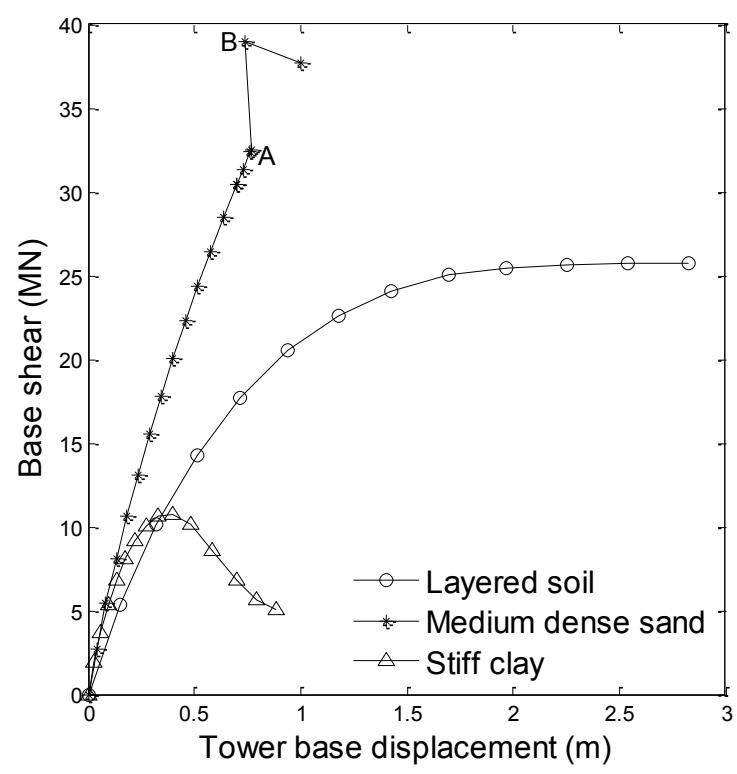

(a) Pushover response curves

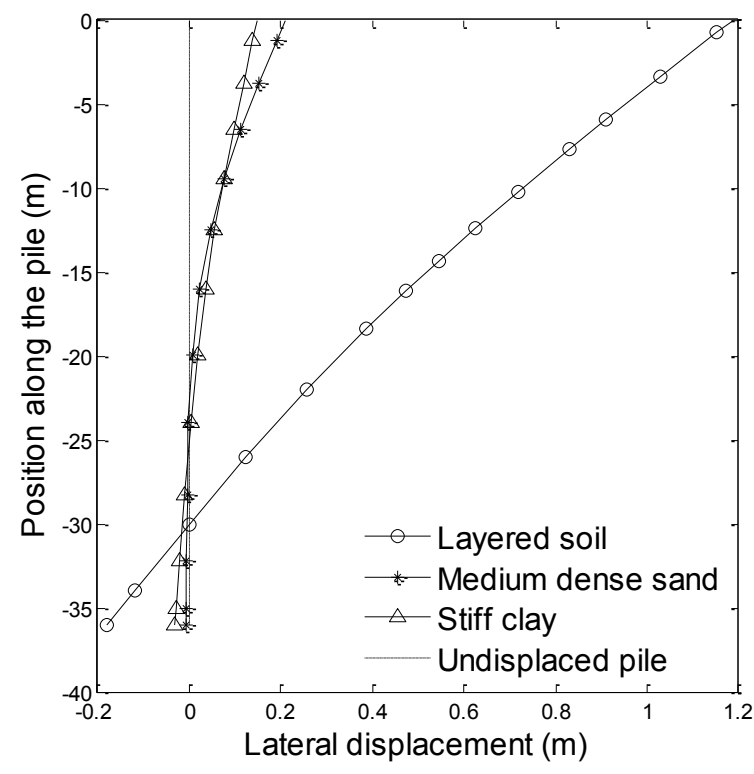

(b) Displacement profiles at collapse

Fig. 7. Pushover analysis of monopile OWT - wave only 

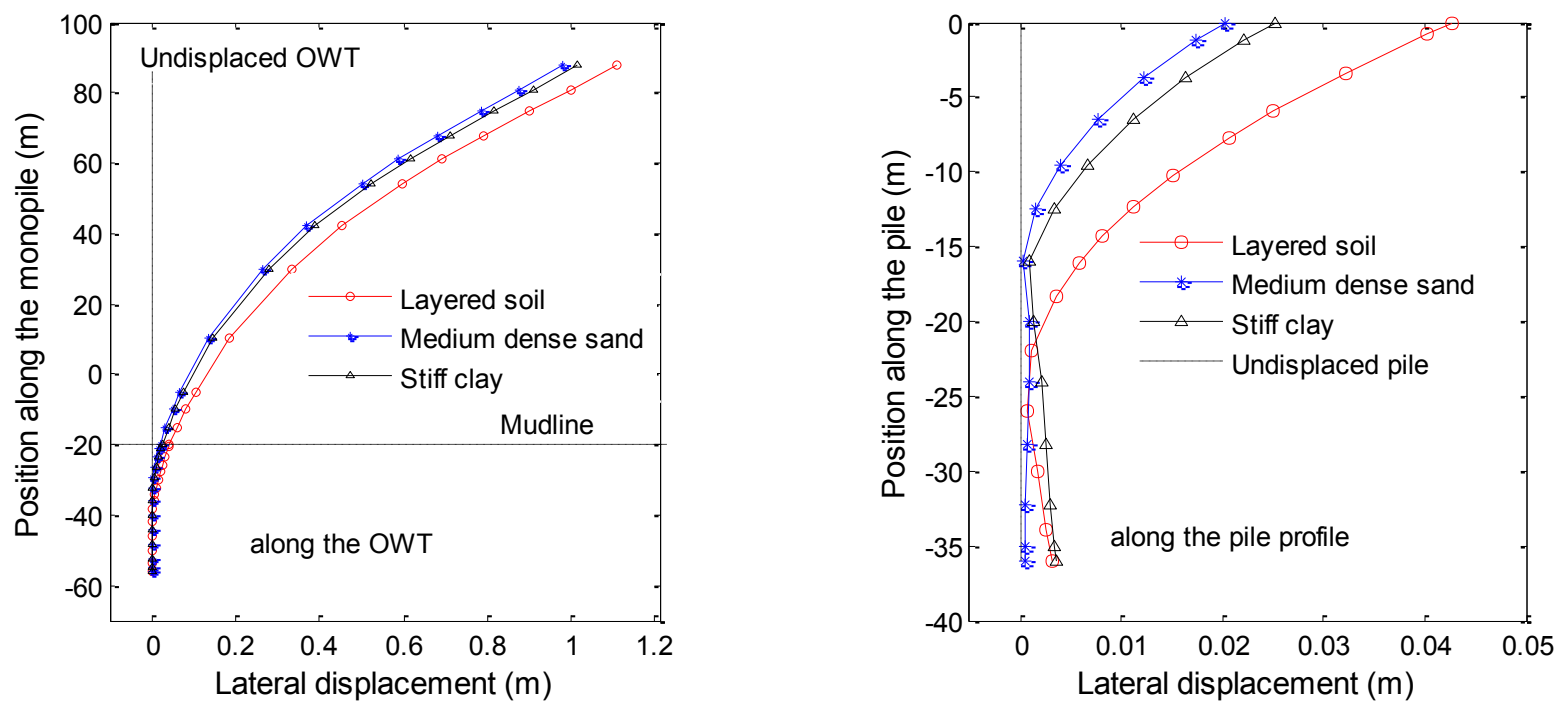

Fig 8. Variation of OWT lateral displacement response with different soil profiles

775

776 
787

788

789
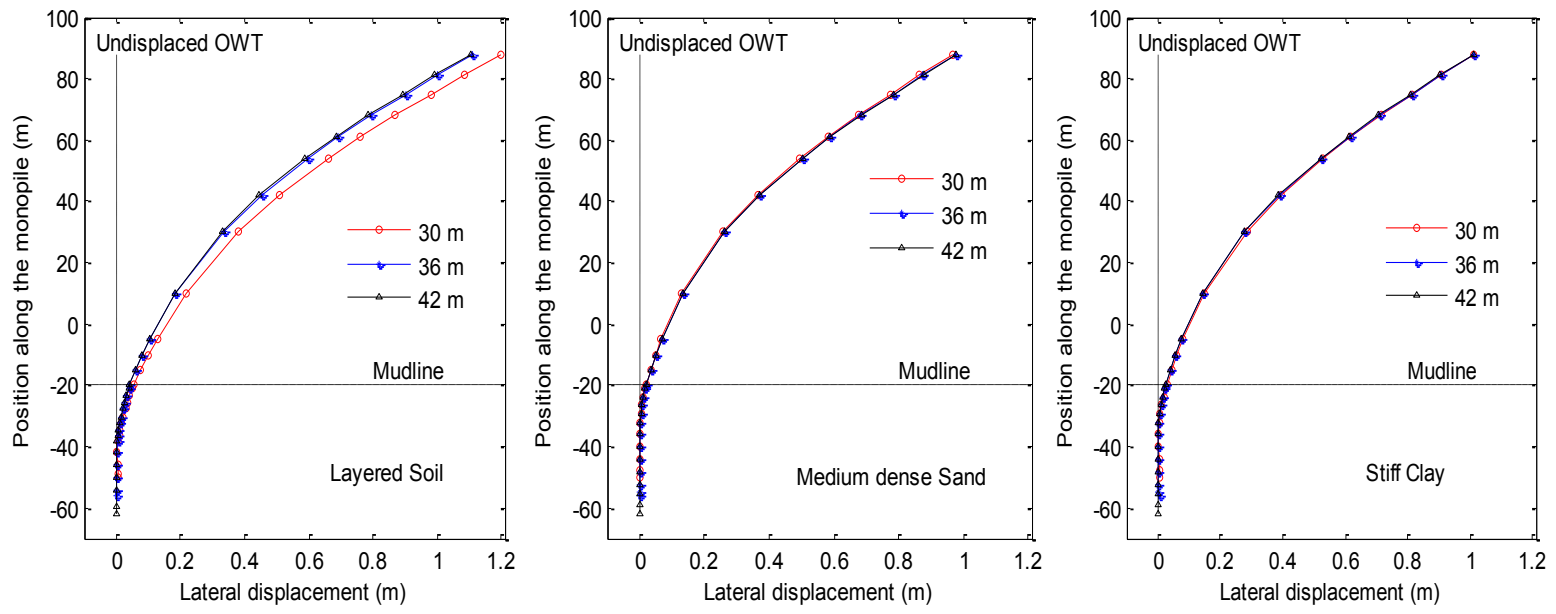

(a) Effect of pile penetration depth
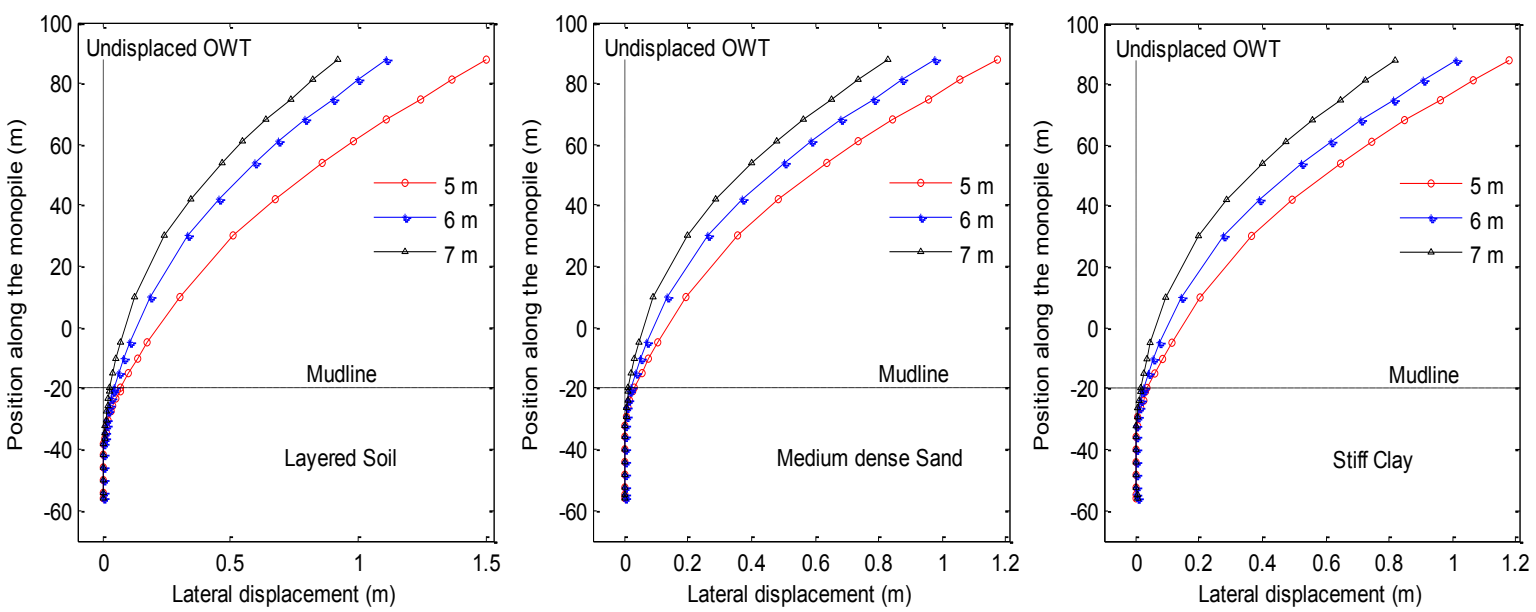

(b) Effect of pile diameter
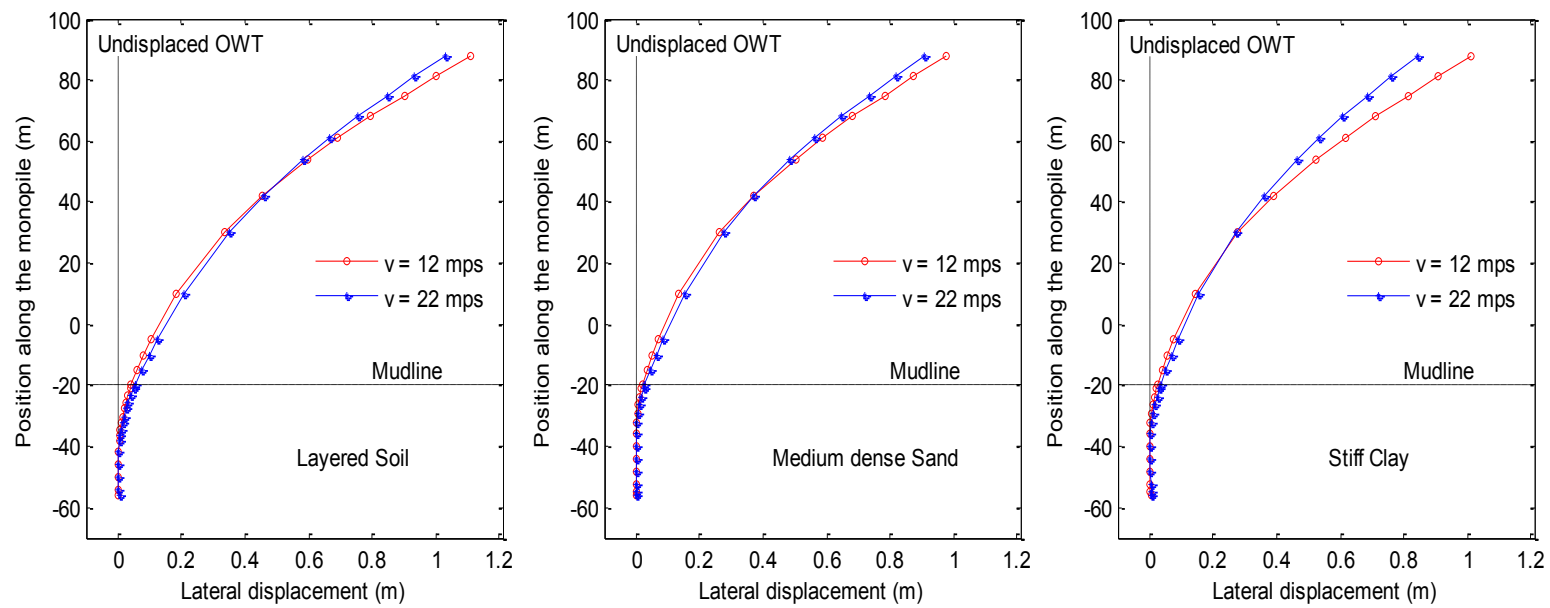

(c) Influence of met-ocean conditions $\left(V_{W}=12 \mathrm{~m} / \mathrm{s}\right.$ with $H_{S}=4 \mathrm{~m}$ and $T_{P}=10 \mathrm{~s}$ and $V_{W}=22 \mathrm{~m} / \mathrm{s}$ with $H_{S}=10 \mathrm{~m}$ and $T_{P}=14 \mathrm{~s}$ )

Fig. 9. Variation of lateral displacement with (a) penetration depth, (b) pile diameter under operational loading and (c) with met-ocean conditions 


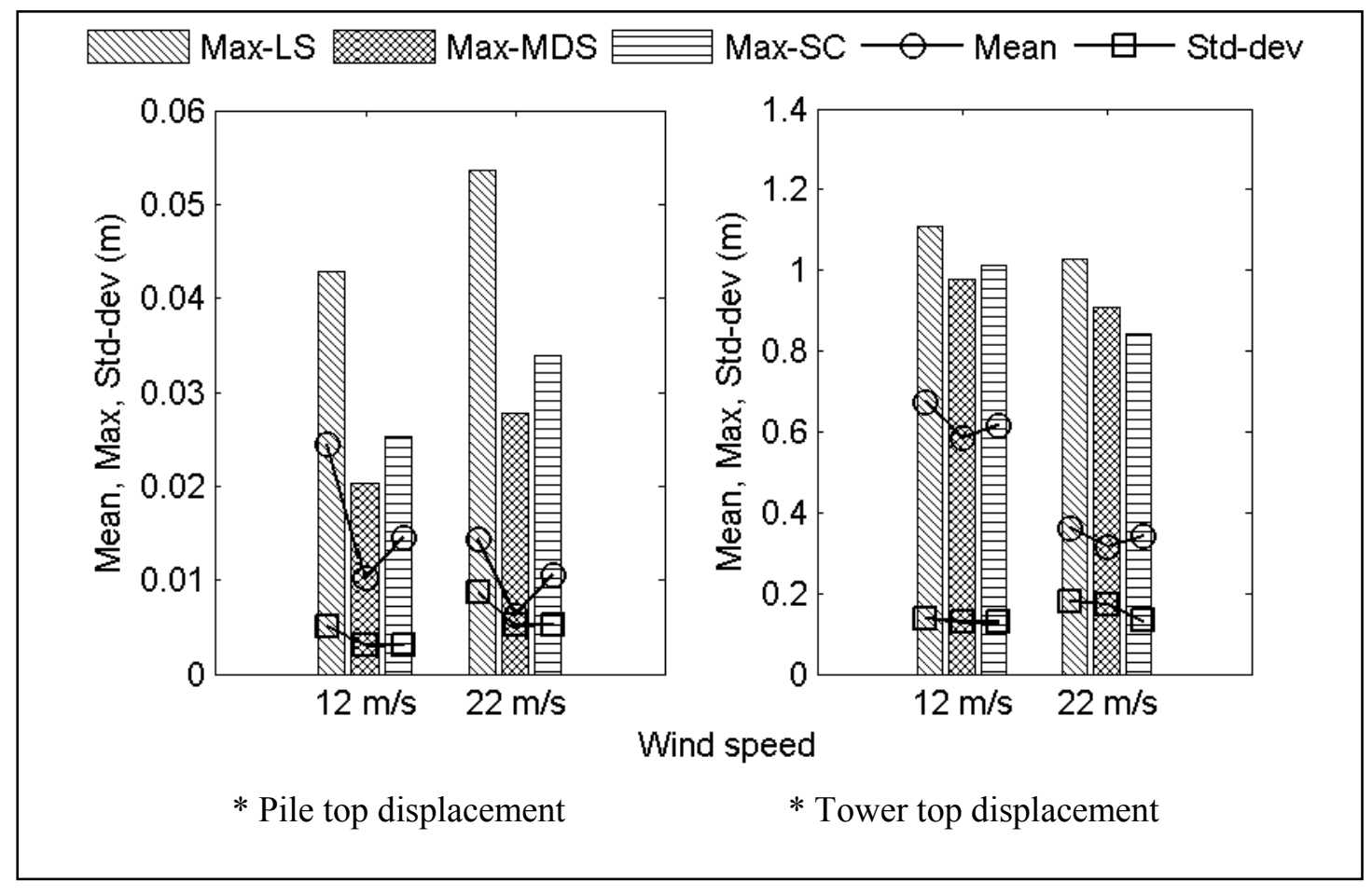

Fig. 10a. Ensemble statistics for lateral displacement

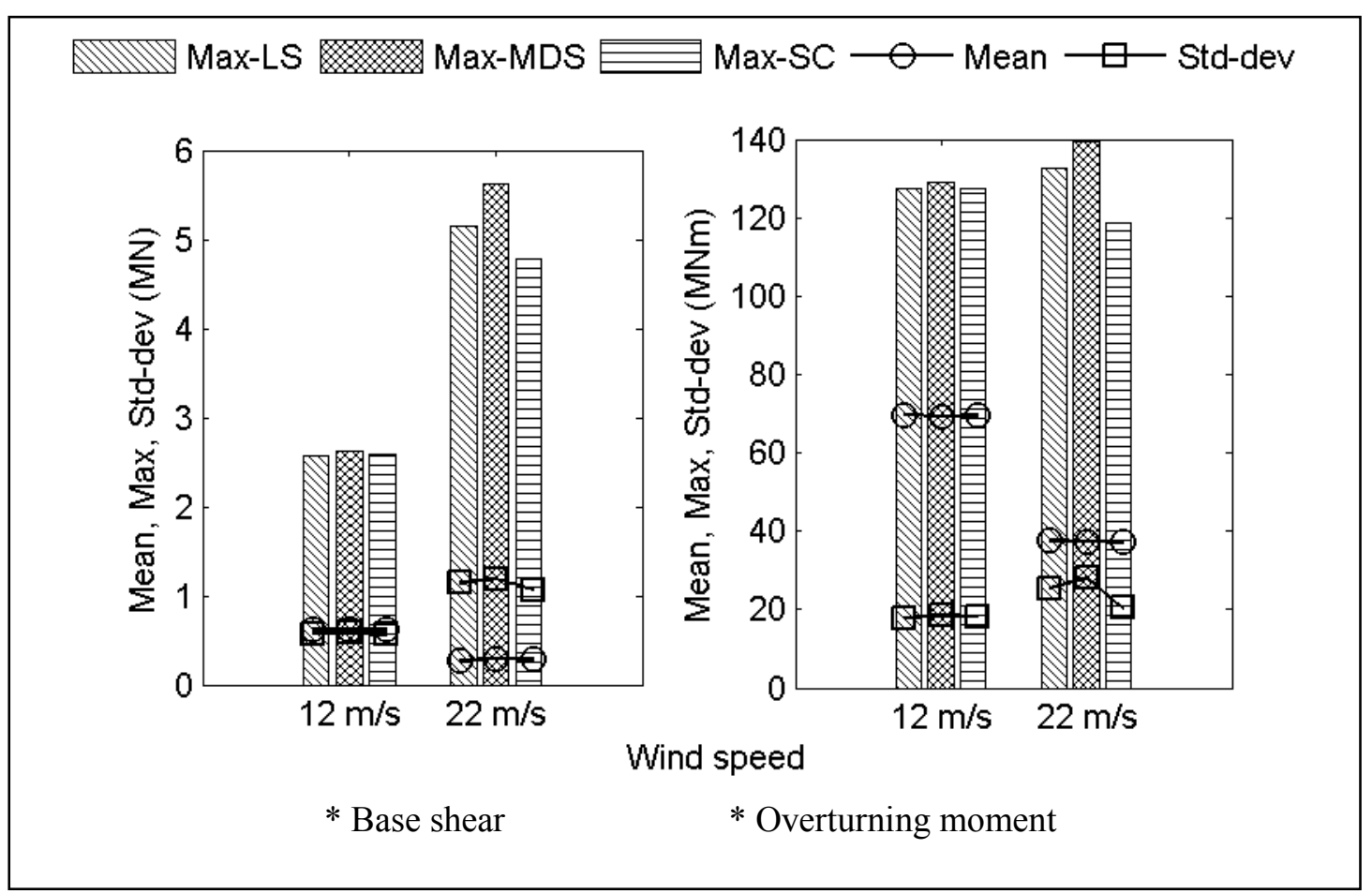

Fig. 10b. Ensemble statistics for base shear and overturning moment

Fig. 10. Ensemble statistics for response of OWT (LS-layered soil, MDS-medium dense soil, SC-stiff clay) ( $V_{W}=12 \mathrm{~m} / \mathrm{s}$ with $H_{S}=4 \mathrm{~m}$ and $T_{P}=10 \mathrm{~s}$ and $V_{W}=22 \mathrm{~m} / \mathrm{s}$ with $H_{S}=10 \mathrm{~m}$ and $T_{P}=14 \mathrm{~s}$ ) 

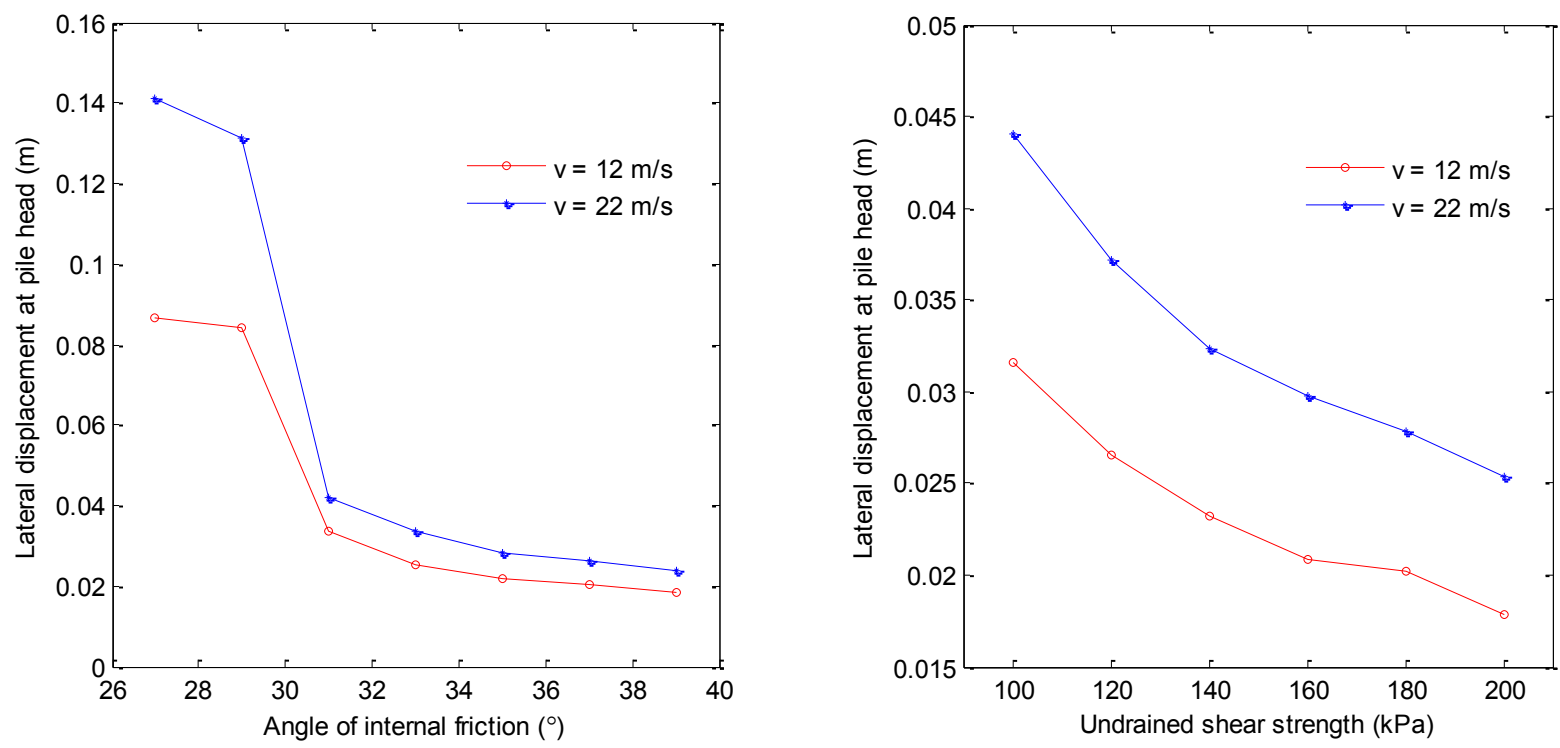

809

(a) Medium dense sand

(b) Stiff clay

Fig. 11. Sensitivity analysis $\left(V_{W}=12 \mathrm{~m} / \mathrm{s}\right.$ with $H_{S}=4 \mathrm{~m}$ and $T_{P}=10 \mathrm{~s}$ and 
Table 1.Properties of the NREL 5 MW baseline OWT (Jonkman et al., 2009)

\begin{tabular}{ll}
\hline Properties & Value \\
\hline Power rating & $5 \mathrm{MW}$ \\
Rotor orientation & 3 bladed, upwind \\
Nacelle mass & 295 tonnes \\
Blade mass & 115 tonnes \\
Rotor diameter & $126 \mathrm{~m}$ \\
Nominal rotor speed & $12.1 \mathrm{rpm}$ \\
Rotational interval & $4.6-12.1 \mathrm{rpm}$ \\
Cut-in wind speed & $3 \mathrm{~m} / \mathrm{s}$ \\
Rated wind speed & $11.4 \mathrm{~m} / \mathrm{s}$ \\
Cut-out wind speed & $25 \mathrm{~m} / \mathrm{s}$ \\
\hline
\end{tabular}

827

828

829

830

Table 2.Properties of soils used for analysis

\begin{tabular}{|c|c|c|c|c|c|c|}
\hline Depth (m) & Type & $\begin{array}{c}\gamma^{\prime} \\
\left(\mathrm{kN} / \mathrm{m}^{3}\right)\end{array}$ & $\Phi\left(^{\circ}\right)$ & $\begin{array}{c}\mathrm{S}_{\mathrm{u}} \\
(\mathrm{kPa})\end{array}$ & $\begin{array}{l}\varepsilon_{50} \\
(\%)\end{array}$ & $\begin{array}{c}K \\
\left(\mathrm{MN} / \mathrm{m}^{3}\right)\end{array}$ \\
\hline \multicolumn{7}{|c|}{ Layered soil } \\
\hline $0.0-1.5$ & Sand & 8 & 20 & & & 5.5 \\
\hline $1.5-5.2$ & Clay & 8 & & 20 & 1.5 & \\
\hline $5.2-6.6$ & Sand & 8.5 & 20 & & & 5.5 \\
\hline $6.6-8.8$ & Clay & 8.5 & & 20 & 1.5 & \\
\hline $8.8-11.7$ & Sand & 9 & 25 & & & 5.5 \\
\hline $11.7-13.1$ & Sand & 9 & 30 & & & 16.6 \\
\hline $13.1-15.6$ & Clay & 8.5 & & 35 & 1.5 & \\
\hline $15.6-16.7$ & Sand & 9 & 25 & & & 5.5 \\
\hline $16.7-37.0$ & Sand & 9 & 30 & & & 16.6 \\
\hline $37.0-49.9$ & Clay & 8.5 & & 110 & 0.5 & \\
\hline \multicolumn{7}{|c|}{ Medium dense sand } \\
\hline $0.0 \rightarrow$ & Sand & 10 & 35 & & & 24.4 \\
\hline \multicolumn{7}{|c|}{ Stiff clay } \\
\hline $0.0 \rightarrow$ & Clay & 8 & & 120 & 0.5 & \\
\hline
\end{tabular}

831 
837

838

839

840

841

842

843

Table 3. Soil profile used for validation

\begin{tabular}{ccccccc}
\hline Depth $(\mathrm{m})$ & Type & $\begin{array}{c}\gamma^{\prime} \\
\left(\mathrm{kN} / \mathrm{m}^{3}\right)\end{array}$ & $\Phi\left(^{\circ}\right)$ & $\begin{array}{c}\mathrm{S}_{\mathrm{u}} \\
(\mathrm{kPa})\end{array}$ & $\begin{array}{c}\varepsilon_{50} \\
(\%)\end{array}$ & $\begin{array}{c}K \\
\left(\mathrm{MN} / \mathrm{m}^{3}\right)\end{array}$ \\
\hline $0.0-5.0$ & Sand & 10 & 33 & & & 16.3 \\
$5.0-14.0$ & Sand & 10 & 35 & & & 24.4 \\
$14.0-36.0$ & Sand & 10 & 38.5 & & & 35.3 \\
\hline
\end{tabular}

Table 4. Tower top displacement comparison

\begin{tabular}{ccccccrcc}
\hline \multirow{2}{*}{ Sl no. } & \multirow{2}{*}{$H_{S}$} & \multirow{2}{*}{$T_{P}(\mathrm{~s})$} & $V_{W}$ & \multicolumn{2}{c}{ USFOS } & \multicolumn{2}{c}{ SESAM Wind } \\
\cline { 5 - 8 } & $(\mathrm{m})$ & & $(\mathrm{m} / \mathrm{s})$ & Mean $(\mathrm{m})$ & Max. $(\mathrm{m})$ & Mean $(\mathrm{m})$ & Max. $(\mathrm{m})$ \\
\hline 1 & 2.7 & 9.5 & 9 & 0.34 & 0.53 & 0.34 & 0.55 \\
2 & 4.0 & 10.0 & 12 & 0.43 & 0.68 & 0.43 & 0.69 \\
3 & 10.0 & 14.0 & 22 & 0.23 & 0.55 & 0.23 & 0.60 \\
\hline
\end{tabular}

Table 5.Apparent fixity depth for different soil types

\begin{tabular}{ccc}
\hline Soil type & AF depth $(\mathrm{m})$ & EI $\left(\mathrm{MN}-\mathrm{m}^{2}\right)$ \\
\hline & Operational sea state \\
\hline Layered & 24.57 & $1.11 \times 10^{6}$ \\
Medium dense sand & 16.59 & $1.06 \times 10^{6}$ \\
Stiff clay & 18.13 & $1.08 \times 10^{6}$ \\
\hline \multicolumn{3}{c}{ Near cut out sea state } \\
\hline Layered & 25.67 & $1.15 \times 10^{6}$ \\
Medium dense sand & 17.42 & $1.12 \times 10^{6}$ \\
Stiff clay & 19.87 & $1.15 \times 10^{6}$ \\
\hline
\end{tabular}

Table 6. Ensemble load statistics for FATBM at mudline

\begin{tabular}{cccccc}
\hline \multirow{2}{*}{ Soil Type } & Max. & Mean. & Std. Dev. & Skewness & Kurtosis \\
\cline { 2 - 6 } & $(\mathrm{MN}-\mathrm{m})$ & $(\mathrm{MN}-\mathrm{m})$ & $(\mathrm{MN}-\mathrm{m})$ & - & - \\
\hline \multicolumn{5}{c}{ Operational sea state } \\
\hline Fixed base & 107.0 & 64.0 & 14.3 & 0.00 & 2.56 \\
Layered & 111.0 & 66.1 & 14.4 & 0.00 & 2.76 \\
Medium dense sand & 107.0 & 65.9 & 13.8 & 0.01 & 2.69 \\
Stiff clay & 108.0 & 66.0 & 13.9 & 0.01 & 2.71 \\
\hline \multicolumn{5}{c}{ Near cut out sea state } \\
\hline Fixed base & 87.8 & 33.9 & 15.7 & 0.00 & 3.07 \\
Layered & 93.2 & 34.1 & 19.5 & -0.10 & 3.15 \\
Medium dense sand & 90.0 & 34.0 & 17.4 & -0.06 & 3.10 \\
Stiff clay & 90.5 & 34.0 & 18.0 & -0.07 & 3.12 \\
\hline
\end{tabular}


Table 7.Natural frequencies and bending modes

Natural frequency $(\mathrm{Hz})$

\begin{tabular}{ccccc}
\hline Bending mode & Fixed base & Layered soil & Medium dense sand & Stiff clay \\
\hline Fore-aft tower bending & 0.30 & 0.25 & 0.26 & 0.26 \\
Side-side tower bending & 0.30 & 0.25 & 0.26 & 0.26 \\
Fore-aft global bending & 2.35 & 1.39 & 1.56 & 1.56 \\
Side-side global bending & 2.35 & 1.39 & 1.56 & 1.56 \\
\hline
\end{tabular}

847

848

849 